\title{
A neural circuit linking two sugar sensors regulates satiety-dependent fructose drive in Drosophila.
}

\author{
Pierre-Yves Musso ${ }^{1}$, Pierre Junca ${ }^{1}$, and Michael D Gordon ${ }^{1,2^{*}}$ \\ 1 University of British Columbia, Canada \\ 2Lead contact \\ *Correspondence: gordon@zoology.ubc.ca
}

\begin{abstract}
Ingestion of certain sugars leads to activation of fructose sensors within the brain of flies, which then sustain or terminate feeding behavior depending on internal state. Here, we describe a three-part neural circuit that links satiety with fructose sensing. We show that AB-FBI8 neurons of the Fan-shaped body display oscillatory calcium activity when hemolymph glycemia is high, and that these oscillations require synaptic input from SLP-AB neurons projecting from the protocerebrum to the asymmetric body. Suppression of activity in this circuit, either by starvation or genetic silencing, promotes specific drive for fructose ingestion. Moreover, neuropeptidergic signaling by tachykinin bridges fan-shaped body activity and Gr43a-mediated fructose sensing. Together, our results demonstrate how a three-layer neural circuit links the detection of two sugars to impart precise satiety-dependent control over feeding behavior.
\end{abstract}

\section{INTRODUCTION}

Animals have evolved multi-layered systems to ensure fulfillment of their nutrient requirements. Among necessary nutrients, carbohydrates afford essential energy and play a major role in survival. Circulating glucose provides fast available energy to support tissue function, and glycemia is tightly regulated. Small variations impact food drive, while prolonged deficiencies lead to tissue damage. Glycemic homeostasis is a well-studied phenomenon under hormonal control, but ultimately the only way to gain energy is through feeding.

Food seeking in response to lowered glycemia is a behavioral consequence that is conserved between mammals and Drosophila (Dus et al., 2013; 2011; Niwano et al., 2009). In flies, several neurons have been suggested to directly sense glucose and impact feeding behavior, including those expressing the peptide DH44 (Dus et al., 2015) and a set co-expressing peptides Corazonin (Crz) and short neuropeptide F (sNPF) dubbed "CN neurons" (Kapan et al., 2012; Oh et al., 2019). Both populations display oscillatory calcium activity in the presence of circulating nutritive sugars and are necessary for post-ingestive nutrient selection (Dus et al., 2015; Oh et al., 2019). MB-MP1 neurons of the mushroom bodies (MBs) also display calcium oscillations, which are thought to signal the availability of energy required for long-term memory formation (Musso et al., 2015; Plaçais and Preat, 2013; Plaçais et al., 2012).

How do changes in circulating glucose alter feeding? The most straightforward way is to elicit changes in sensitivity and attractiveness to specific food-related cues. Important examples of this phenomenon have been described in both the olfactory system (Ko et al., 2015; Lin et al., 
2019; Root et al., 2011; Sayin et al., 2019; Slankster et al., 2020), and the gustatory system of flies (Inagaki et al., 2012; 2014; Jaeger et al., 2018; LeDue et al., 2016; Musso et al., 2019). In taste, a particular area of focus has been sugar detection. Sugars are first detected by gustatory receptor neurons located on the fly proboscis and legs, which initiate feeding, and then by GRNs in the pharynx, which sustain ingestion (Dahanukar et al., 2001; 2007; Jiao et al., 2008; Kwon et al., 2014; LeDue et al., 2015; Marella et al., 2006; Park and Kwon, 2011; Scott, 2018; Thorne et al., 2004; Wang et al., 2004b). The responses of sugar-sensing GRNs and several examples of second-order sugar neurons are enhanced by food deprivation (Inagaki et al., 2014; Kain and Dahanukar, 2015; Yapici et al., 2016).

Starvation also modulates the response of neurons in the lateral protocerebrum of the brain that express one particular member of the gustatory receptor (GR) family, Gr43a (Miyamoto et al., 2012). Gr43a is unusual among the nine identified sugar-sensing GRs in that it is specifically tuned to fructose. Activation of Gr43a brain neurons leads to feeding cessation in fed flies and feeding prolongment in those that are starved (Miyamoto et al., 2012). This supports a model where circulating fructose levels rise when a fly eats sugary food, and trigger activation of Gr43a brain neurons that then either prolong or terminate feeding, depending on satiety state. One appealing aspect of this model is that it cleanly separates detection of ingested sugars from detection of satiety. Naturally-occurring sweet foods generally contain both fructose and glucose, as well as sucrose, which is a dimer of the two. Thus, circulating fructose may serve as the cue for recently ingested sugar and vary widely, while tightly-controlled glucose levels provide an indicator of satiety. However, the circuitry connecting starvation and glycemia with fructose sensing by Gr43a brain neurons has not been explored.

In this study, we find that $A B-F B I 8$ ( $v \Delta A \_a$ ) neurons, which compose layers 8 and 9 of the central complex structure called the Fan-Shaped body, act as central glucose sensors that couple satiety state with fructose drive. Fed flies display AB-FBI8 calcium oscillations and have equal preference between feeding on fructose or glucose. However, prolonged starvation suppresses AB-FBI8 oscillations and leads to a strong shift in preference towards fructose. We show that silencing $A B-F B \mid 8$ neurons mimics the fructose preference shift seen upon prolonged starvation and that $A B-F B I 8$ activity is modulated by glutamatergic input from SLP-AB neurons of superior lateral protocerebrum. Finally, we demonstrate that the effect of AB-FBI8 neurons on fructose feeding is mediated by release of the neuropeptide tachykinin, which signals to Gr43a brain neurons. The linking of two specific sugar sensors in this three-neuron circuit imparts precise hunger-dependent control over sugar consumption.

\section{RESULTS}

\section{Starvation regulates Fan-Shaped Body oscillations.}

In order to identify novel circuits controlling carbohydrate intake, we surveyed calcium activity in candidate brain areas using GCaMP6f expression under control of GAL4 lines from the Janelia Flylight collection (Chen et al., 2013; Jenett et al., 2012). This revealed oscillatory activity in dorsal fan-shaped body (dFB) neurons labelled by R70H05-GAL4 (Figure 1A). Oscillations were strong in fed flies and dramatically reduced in intensity and frequency following prolonged starvation of 30 hours (Figure 1B-F; Figure S1A,B; supplemental movies 1,2). We noted asymmetry in the oscillations, with asynchronous activity on the right and left side as well as a tendency for the right part of the dFB to show higher frequencies than the left (Figure S1A,B; supplemental movie 1). Interestingly, flies starved for only 18 hours displayed oscillations similar to those of fed flies (Figure 1B-F; Figure S1A,B). Since starvation is associated with lower 
hemolymph carbohydrate levels (Dus et al., 2011; 2013; Rovenko et al., 2015a; 2015b), we hypothesized that dFB neurons may act as brain glucose sensors. Knocking down Glucose transporter type 1 (Glut1) and Hexokinase $\mathrm{C}(\mathrm{HexC})$ within dFB reduced their oscillations to a level comparable to prolonged starvation, supporting a role for glucose sensing in dFB regulation (Figure 1B-G; Figure S1A,B) (Dus et al., 2015; Escher and Rasmuson-Lestander, 1999; Moser et al., 1980; Oh et al., 2019; Volkenhoff et al., 2018).

\section{AB-FBI8 drives starvation-dependent changes in fructose feeding.}

The dFB neurons labelled by R7OH05-GAL4 occupy layers 8 and 9 of the FB and project to the Asymmetric Body ( $A B$ ), identifying them as $A B-F B I 8$ (or $v \triangle A$ a) neurons (Figure 1A) (Hulse et al., 2020; Jenett et al., 2012; Wolff and Rubin, 2018; Wolff et al., 2015). To test whether ABFBI8 neurons link satiety signals to changes in behavior, we silenced them and measured feeding using a modified version of FlyPAD where food interactions were calculated using the algorithm we developed for the STROBE (Figure 2B-C) (Itskov et al., 2014; Jaeger et al., 2018; Musso et al., 2019). Flies conditionally expressing the inward rectifying potassium channel Kir2.1 (Baines et al., 2001; McGuire et al., 2004) under the control of R70H05-GAL4 displayed an increased number of interactions with sucrose at low concentrations ( 5 and $50 \mathrm{mM}$ ) but not at $1 \mathrm{M}$ (Figure 2D). Interestingly, AB-FBI8 silencing did not affect feeding on either L-glucose (sweet but not caloric) or sorbitol (caloric but not sweet), but dramatically elevated interactions with a mixture of the two (Figure 2E-G) (Dus et al., 2013; Musso et al., 2015; 2017). Given that the sweet taste of sucrose and L-glucose stimulates feeding initiation, we suspected that sorbitol and sucrose were being detected post-ingestively to trigger enhanced feeding in $A B-$ FBI8-silenced flies. D-glucose failed to trigger excess feeding by AB-FBI8-silenced flies, indicating that energy alone was not sufficient for this post-ingestive effect (Figure $2 \mathrm{H}$ ). However, AB-FBI8 silencing produced strong over feeding on fructose, which is quickly metabolized from both sucrose and sorbitol (Figure 2I). Thus, we posited that AB-FBI8 are part of a circuit that links satiety-dependent changes in hemolymph glucose levels with a flies' response to post-ingestive changes in hemolymph fructose.

If $A B-F B \mid 8$ produces satiety signals that inhibit post-ingestive fructose sensing, then silencing of $A B-F B I 8$ should release this inhibition and produce increased relative preference for fructose over glucose. We found that flies expressing Kir2.1 under control of R7OH05-GAL4 displayed a strong preference for fructose over glucose at concentrations of $5 \mathrm{mM}$ and $50 \mathrm{mM}$, but not $1 \mathrm{M}$, while control flies showed nearly equal preference for the two sugars at all concentrations (Figure 3A-B; Figure S1C). Since R7OH05-GAL4 drives expression in additional neurons outside the $A B-F B I 8$ population, we verified the causal role for AB-FBI8 by measuring glucose versus fructose preference following silencing with two other drivers (R70H05-LexA and VT005528-GAL4) and a split construction that we built (FB-split), all of which specifically label AB-FBI8 neurons (Figure S1D-F). In each case, AB-FBI8 silencing led to a strong preference for fructose over glucose. We also verified that AB-FBI8 neurons labeled by FB-split showed oscillatory activity that was reduced following prolonged starvation (Figure S2A-C).

Given that $A B-F B I 8$ oscillations are suppressed upon starvation, we wondered whether $A B-F B I 8$ silencing evoked a starvation-like state in flies. Thus, we subjected AB-FBI8-silenced and control flies to different periods of food deprivation and then measured their preference for fructose versus glucose (Figure $3 \mathrm{C}$ ). This revealed that both $\mathrm{AB}-\mathrm{FB}$ I8-silenced and control flies prefer fructose over glucose following food deprivation of 24 hours or more (Figure 3D). However, at 16 hours of starvation, a condition under which AB-FBI8 show fed-like oscillations 
(Figure 1B), AB-FBI8-silenced flies preferred fructose, while control flies fed on both options equally. These results indicate that flies develop a relative preference for fructose as starvation progresses, and that $\mathrm{AB}-\mathrm{FB} 8 \mathrm{8}$ silencing shifts this curve to the left, producing fructose preference at lower levels of starvation (Figure 3D). Notably, preference between fructose and glucose was equal for all groups following 0 or 8 hours of starvation. We suspect that this is because a threshold of consumption needs to be met for post-ingestive fructose sensing to stimulate further feeding, and that feeding initiation is controlled independently of $A B-F B I 8$ activity. Thus, flies without sufficient food deprivation would not consume enough fructose to trigger AB-FBI8-regulated feeding circuits. Indeed, the proboscis extension reflex (PER) to fructose and glucose remained unchanged following $A B-F B \mid 8$ silencing, indicating that $A B-F B \mid 8$ do not regulate peripheral sensitivity to sugars or sensory-driven feeding initiation, and likely rather modulate responses to post-ingestive cues (Figure S2D,E).

Although food interactions measured on the FlyPAD strongly correlate with consumption, we next sought to confirm that $\mathrm{AB}-\mathrm{FB} / 8$ silencing genuinely promotes fructose ingestion. As expected, AB-FBI8-silenced flies preferentially consumed fructose over glucose in a dye-based binary choice feeding assay, while controls consumed the two sugars equally (Figure S2F). Moreover, control flies preferentially consumed fructose over glucose when AB-FBI8 activity was suppressed by 43 hours of starvation, and thermogenetic activation of AB-FBI8 with TRPA1 suppressed this elevated fructose feeding (Figure $\mathrm{S} 2 \mathrm{G}$ ). This demonstrates that AB-FBI8 activity is sufficient to inhibit fructose sensing mechanisms.

To link the behavioral role of AB-FBI8 back to their function in glucose sensing, we measured the feeding preference of flies following RNAi knock down of Glut1 or HexC in the AB-FBI8. Consistent with their effects on AB-FBI8 oscillations, knock-down of either gene promoted strong preference for fructose over glucose in the FlyPAD (Figure 3E-F; Figure S3A-B). This suggests that changes in $A B-F B \mid 8$ activity mediated by glucose sensing drive effects on fructose feeding. Altogether, our results suggest that starvation-induced reduction of hemolymph glucose suppresses AB-FBI8 activity, which in turn promotes fructose feeding (Figure 3G).

\section{SLP-AB synaptically modulate AB-FBI8 oscillations.}

To examine the broader circuit in which $A B-F B \mid 8$ are regulating fructose consumption, we used UAS-synaptotagmin-GFP (UAS-Syt-GFP) and UAS-Denmark to label pre- and post-synaptic areas, respectively. This demonstrated that the AB-FBI8 presynaptic terminals reside in layer 8 of the Fan-Shaped Body, while their dendrites primarily occupy the $A B$, a structure known to be required for energetically-costly long-term memory (Figure 4A)(Burke and Waddell, 2011; Mery and Kawecki, 2005; Musso et al., 2015; Pascual et al., 2004; Plaçais and Preat, 2013; Plaçais et al., 2017). In search of inputs to AB-FBI8, we examined the SLP-AB population, which has arborizations in the Superior lateral protocerebrum (SLP) and the AB (Jenett et al., 2012; Wolff and Rubin, 2018). We generated a split-GAL4 labelling SLP-AB neurons, and confirmed the location of their dendrites in the SLP and axon terminals in the AB (Figure 4B). Trans-Tango driven by this driver revealed post-synaptic neurons in layer 8 of the Fan-Shaped Body, suggesting that AB-FBI8 are postsynaptic to SLP-AB (Figure 4C)(Talay et al., 2017). Moreover, GFP-reconstitution across synaptic partners (GRASP) between AB-FBI8 and SLP-AB revealed a single point of contact in the $A B$ (Figure 4D). Finally, silencing SLP-AB neurons reduced the oscillatory activity of $\mathrm{AB}-\mathrm{FBI} 8$ in fed flies, demonstrating functional connectivity between the two neuron populations (Figure 4E,H; Figure S4). 
Next, we addressed whether the modulatory action of SLP-AB neurons on AB-FBI8 affects behavior. Indeed, silencing SLP-AB neurons reproduced all the behavioral phenotypes observed from $\mathrm{AB}-\mathrm{FB} 18$ silencing with R70H05-GAL4: increased feeding interactions with sucrose, fructose, and a mixture of L-glucose and sorbitol, but not D-glucose, L-glucose, or sorbitol alone (Figure S5A-H); no effect on taste sensitivity to fructose nor D-glucose (Figure S5I-J); and enhanced preference for fructose over glucose (Figure 5A; Figure S5K). Silencing SLP-AB with an independent driver (R72A10-LexA (Jenett et al., 2012)) also reproduced the fructose feeding preference, verifying that SLP-AB were responsible for this phenotype (Figure $\mathrm{S} 5 \mathrm{~L})$. Moreover, like $\mathrm{AB}-\mathrm{FBI8}$, SLP-AB activation reduced fructose feeding preference in strongly starved flies (Figure S5M).

Knocking down Glut1 and Hexokinase $C$ in SLP-AB did not impact behavior, suggesting that these neurons do not sense hemolymph D-glucose (Figure S6A,B). However, knocking down the vesicular glutamate transporter (Vglut) in SLP-AB promoted fructose feeding preference (Figure 5B; Figure S6C-E). GluCla, a ligand gated chloride channel, is one of the few glutamate receptors expressed in FB (Cully et al., 1996; Kahsai et al., 2012; Kondo et al., 2020). Knockdown of GluCla in $\mathrm{AB}-\mathrm{FBI} 8$ also induced fructose preference and decreased $\mathrm{AB}-\mathrm{FBI} 8$ oscillations (Figure 5C,D; Figure S6F-H). Altogether, these data suggest that SLP-AB impact behavior by promoting AB-FBI8 oscillations via the action of glutamate on GluCl $\alpha$ (Figure $5 \mathrm{E}$ ).

\section{AB-FBI8 regulates fructose feeding via tachykinin signalling to Gr43a neurons.}

Initiating trans-tango from the $A B-F B \mid 8$ did not show any clear post-synaptic targets, with the exception of the noduli (Figure S7A,B). Such an absence of trans-tango signal suggests that AB-FBI8 may function non-synaptically through peptide secretion, which is characteristic of calcium oscillatory cells (Thorner et al., 1988). This is supported by EM data revealing postsynaptic connections only within the $\mathrm{FB}$ and the $\mathrm{AB}$, and a previous report of tachykinin and sNPF expression in AB-FBI8 (Clements et al., 2020; Kahsai et al., 2012; Kahsai and Winther, 2011; Qi et al., 2020; Winther et al., 2003). Using two independent AB-FBI8 drivers, we found that knock down of Tk, but not SNPF, reproduced the fructose preference phenotype seen with AB-FBI8 silencing (Figure 6 and Figure S7C,D). Moreover, a recent study showed elevated Tk mRNA expression in fed and re-fed flies compared to those that had been starved (Qi et al., 2020).

Flies express two receptors for Tk: TkR86C (or NKD)(Asahina et al., 2014; Li et al., 1991; Monnier et al., 1992; Poels et al., 2009) and the widely expressed TkR99D (or DTKR) (Birse et al., 2006; Ignell et al., 2009; Im et al., 2015; Qi et al., 2020; Song et al., 2014). Since Gr43aexpressing neurons in the lateral protocerebrum are the only known post-ingestive fructose sensors, we knocked down each receptor specifically in Gr43 brain neurons using Gr43a-GAL4 combined with Cha7.4kb-GAL80 (Miyamoto et al., 2012) (Figure S8A-B). This revealed a requirement for TkR99D but not TkR86C in restricting fructose intake (Figure 7A,C and Figure S8). In vivo, TkR99D has been demonstrated to have inhibitory activity (Birse et al., 2006; Ignell et al., 2009; Song et al., 2014). Thus, we postulate that under fed conditions, Tk released from AB-FBI8 inhibits brain Gr43a neurons, preventing them from responding to circulating fructose (Figure 7C).

\section{Brain Gr43a neurons acutely regulate fructose feeding.}

To understand how Gr43a brain neurons impact feeding, we first tested their role in the choice between fructose and glucose using the FlyPAD. Flies expressing Kir2.1 under control of 
Gr43a-GAL4 and Cha ${ }^{7.4 k b}-G A L 80$ strongly prefer glucose over fructose, indicating that Gr43a brain neurons are necessary for normal fructose feeding (Figure 8A). Conversely, closed-loop activation of Gr43a brain neurons in the sip-triggered optogenetic behavior enclosure (STROBE) is sufficient to promote feeding (Figure 8B). In this experiment, flies expressing the red-light activated channel CsChrimson in Gr43a brain neurons and previously fed the obligate CsChrimson cofactor all-trans retinal were compared to a control group without retinal (Klapoetke et al., 2014). Flies could feed on either of two identical drops of $1 \%$ agar, one of which was coupled to red light activation. We found that the retinal-fed group robustly preferred the light-triggering agar, while the control group showed no preference (Figure 8B).

\section{DISCUSSION}

Regulation of energy intake is a complex process involving food search, an animal's internal state, and the sensory qualities of food. Fructose, either consumed directly or rapidly metabolized from precursors, promotes feeding through activation of a brain fructose sensor called Gr43a (Miyamoto et al., 2012). Here we describe how a neuronal network composed of neurons in the Fan-shaped body and asymmetric body contributes to energy homeostasis by detecting satiety-dependent changes in hemolymph glucose and modulating fructose drive (Figure 8C).

\section{The FB is a very organized yet incompletely understood structure}

The central complex, which is comprised of the FB, the protocerebral bridge (PB), the ellipsoid body, and the noduli, is regarded as a center for sensory motor integration that functions in goal directed behavior (Fisher et al., 2019; Honkanen et al., 2019; Hulse et al., 2020; Pfeiffer and Homberg, 2014; Sun et al., 2020; Weir and Dickinson, 2015; Wolff et al., 2015). The FB is organized in nine horizontal layers and nine vertical columns. FB large field neurons of layers 1 to 3 , and inputs to these layers from the $\mathrm{PB}$, encode flight direction and general sensory orientation (Currier et al., 2020; Weir and Dickinson, 2015). FB layers 6 and 7 are well known to regulate sleep and arousal (Berry et al., 2015; Donlea et al., 2011; Ueno et al., 2012), locomotor control (Strauss, 2002), courtship (Sakai and Kitamoto, 2006) and visual memory (Li et al., 2009; Liu et al., 2006; Wang et al., 2008). Layer 6 also plays a role in avoiding conditioned odors, while layers 1,2, 4 and 5 respond to electric stimuli and are required for innate odor avoidance (Hu et al., 2018). However, the function of the most dorsal FB layers (8 and 9), mostly innervated local tangential neurons and $A B-F B I 8$ (or $v \Delta A$ a), remained poorly understood (Hulse et al., 2020; Jenett et al., 2012; Wolff and Rubin, 2018; Wolff et al., 2015). Our results demonstrate an involvement of these layers in feeding regulation.

\section{SLP-AB and $A B-F B \mid 8$ provide insight on asymmetric body function}

We find that $A B-F B I 8$ oscillations require glutamatergic input from SLP-AB projections to the asymmetric body. Described for the first time in 2004 (Pascual et al., 2004), very little is known about the asymmetric body. $92.4 \%$ of flies display asymmetry in this structure, with the body present only in the right hemisphere, while $7.6 \%$ also have a body on the left side (Pascual et al., 2004). We noted that oscillations in the AB-FBI8 display a tendency to be faster on the right side, with clearly asynchronous activity that may reflect their asymmetric input from SLP-AB. Interestingly, the small proportion of flies displaying symmetry have defects in long-term memory, a process that is known to require energy (Burke and Waddell, 2011; Mery and Kawecki, 2005; Musso et al., 2015; Pascual et al., 2004; Plaçais and Preat, 2013; Plaçais et al., 2017). We speculate that these symmetric flies may have a dysfunctional SLP-AB to AB-FBI8 connection, resulting in impaired Tk release. This could impact LTM either directly or through 
changes in feeding (Nässel et al., 2019). A role for TK in memory has been demonstrated in honeybees (Boerjan et al., 2010; Brockmann et al., 2009; Takeuchi et al., 2004) and mammals (Lénárd et al., 2018), and TkR86C appears to be expressed in serotonergic paired neurons (SPN) known to interact with MB-MP1 neurons required for long-term memory formation (Poels et al., 2009; Scheunemann et al., 2018). Tk also acts through TkR99D to modulate activity in neurons producing i-like peptides (Birse et al., 2011; Qi et al., 2020), which impact LTM formation (Chambers et al., 2015; Eschment et al., 2020).

Surprisingly, modulation of AB-FBI8 oscillations by SLP-AB requires glutamatergic signaling through GluCla. This suggests that either inhibition from SLP-AB is required for $A B-F B I 8$ oscillatory activity or AB-FBI8 have an unusual chloride reversal potential. Interestingly, GluCl $\alpha$ has been previously implicated in ON/OFF responses of the visual system, demonstrating a role in regulating cell excitability (Molina-Obando et al., 2019). Further study will be required to fully understand this connection, along with the source of input to SLP-AB in the protocerebrum.

\section{A dual role for 2 carbohydrates}

Since glucose is the primary circulating energy source, one might intuitively expect that enhancing feeding in response to post-ingestive glucose detection would be the most efficient means of energy uptake. However, using elevation of hemolymph glucose as a signal to continue feeding is problematic because glucose levels are tightly regulated, and elevated glucose serves as a signal of satiety. On the other hand, circulating fructose can vary widely in response to ingestion and can therefore be a more reliable indicator of recent sugar intake (Miyamoto et al., 2012). Moreover, fructose typically co-exists with other nutritive sugars in common food sources and can therefore serve as an effective proxy for carbohydrate ingestion. Thus, the separation of glucose as a satiety indicator and fructose as marker of sugar consumption removes the potential ambiguity of each as a signal. To enable sustained feeding on a rich sugar source, such a mechanism would require that ingestion of sugars and the subsequent activation of Gr43a brain neurons rapidly promotes feeding behavior. Our results support this idea in two main ways. First, silencing of AB-FBI8 neurons by genetic manipulation or prolonged starvation produces Gr43a-dependent fructose preference within the first 10 minutes of a FlyPAD assay (Figure S1C). Second, closed-loop optogenetic activation of Gr43a brain neurons was sufficient to produce a strong positive preference within 60 minutes in the STROBE (Figure 8B).

Interestingly, glucose and fructose also have differential effects in mammals, where glucose ingestion promotes satiety by repressing the secretion of the hunger hormone ghrelin and stimulating the secretion of satiety hormones such as leptin or insulin (Merino et al., 2019). Fructose, however, induces a reduction in ghrelin and can promote over-feeding (Merino et al., 2019). Similarly, hypothalamic AMPK is described as functioning as an energy sensor and its inhibition by glucose administration or leptin and insulin promotes anorexigenic behavior. Conversely, fructose administration activates AMPK and promotes orexigenic behavior (Burmeister et al., 2013; Cawley, 2012; Cha et al., 2008; Minokoshi et al., 2004; Wang et al., 2004a). The first description of fly Gr43a neurons noted their orexinegenic activity and suggested a potential functional homology with the hypothalamus (Miyamoto et al., 2012). In the present study, we uncovered a multi-layered neural system centered on a brain energy sensor (AB-FBI8), whose activation by glucose leads to anorexigenic behavior through inhibition of the brain fructose sensor Gr43a. Thus, our results are consistent with at least partial functional homology between the mammalian hypothalamus and brain Gr43a neurons of the fly. 


\section{SUPPLEMENTAL INFORMATION}

Supplemental information includes eight figures that can be found in an associated file, and two supplemental movies.

\section{ACKNOWLEDGEMENTS}

We thank members of the lab for their comments on the manuscript. We thank Dr. Pierre-Yves Plaçais for providing the MATLAB code for oscillation analysis and for his help in processing. We also thank Hubert Amrein, the Bloomington stock center, and the Vienna Drosophila Resource Center for fly stocks. This work was funded by the Natural Sciences and Engineering Research Council (NSERC) of Canada (RGPIN-2016-03857 and RGPAS-49246-16) and a Michael Smith Foundation for Health Research Scholar Award to M.D.G.

\section{AUTHOR CONTRIBUTIONS}

Conceptualization, P-Y.M; Methodology, P-Y.M and M.D.G; Formal analysis, P-Y.M, P.J, and M.D.G; Investigation, P-Y.M, and P.J; Writing, P-Y.M and M.D.G; Visualization, P-Y.M; Supervision, M.D.G; Funding acquisition, M.D.G.

\section{DECLARATION OF INTERESTS}

Authors declare no conflicts of interests.

\section{REFERENCES}

Asahina, K., Watanabe, K., Duistermars, B.J., Hoopfer, E., González, C.R., Eyjólfsdóttir, E.A., Perona, P., and Anderson, D.J. (2014). Tachykinin-expressing neurons control male-specific aggressive arousal in Drosophila. Cell 156, 221-235.

Baines, R.A., Uhler, J.P., Thompson, A., Sweeney, S.T., and Bate, M. (2001). Altered electrical properties in Drosophila neurons developing without synaptic transmission. J. Neurosci. 21, 1523-1531.

Berry, J.A., Cervantes-Sandoval, I., Chakraborty, M., and Davis, R.L. (2015). Sleep Facilitates Memory by Blocking Dopamine Neuron-Mediated Forgetting. Cell 161, 1656-1667.

Birse, R.T., Johnson, E.C., Taghert, P.H., and Nässel, D.R. (2006). Widely distributed Drosophila Gprotein-coupled receptor (CG7887) is activated by endogenous tachykinin-related peptides. J Neurobiol $66,33-46$.

Birse, R.T., Söderberg, J.A.E., Luo, J., Winther, A.M.E., and Nässel, D.R. (2011). Regulation of insulinproducing cells in the adult Drosophila brain via the tachykinin peptide receptor DTKR. J. Exp. Biol. 214, 4201-4208.

Boerjan, B., Cardoen, D., Bogaerts, A., Landuyt, B., Schoofs, L., and Verleyen, P. (2010). Mass spectrometric profiling of (neuro)-peptides in the worker honeybee, Apis mellifera. Neuropharmacology 58, 248-258.

Brockmann, A., Annangudi, S.P., Richmond, T.A., Ament, S.A., Xie, F., Southey, B.R., Rodriguez-Zas, S.R., Robinson, G.E., and Sweedler, J.V. (2009). Quantitative peptidomics reveal brain peptide signatures of behavior. Proc. Natl. Acad. Sci. U.S.a. 106, 2383-2388.

Burke, C.J., and Waddell, S. (2011). Remembering nutrient quality of sugar in Drosophila. Curr. Biol. 21, 746-750. 
Burmeister, M.A., Ayala, J., Drucker, D.J., and Ayala, J.E. (2013). Central glucagon-like peptide 1 receptor-induced anorexia requires glucose metabolism-mediated suppression of AMPK and is impaired by central fructose. Am J Physiol Endocrinol Metab 304, E677-E685.

Cawley, N.X. (2012). Sugar making sugar: gluconeogenesis triggered by fructose via a hypothalamicadrenal-corticosterone circuit. Endocrinology 153, 3561-3563.

Cha, S.H., Wolfgang, M., Tokutake, Y., Chohnan, S., and Lane, M.D. (2008). Differential effects of central fructose and glucose on hypothalamic malonyl-CoA and food intake. Proc. Natl. Acad. Sci. U.S.a. 105, 16871-16875.

Chambers, D.B., Androschuk, A., Rosenfelt, C., Langer, S., Harding, M., and Bolduc, F.V. (2015). Insulin signaling is acutely required for long-term memory in Drosophila. Front Neural Circuits 9, 8.

Chan, R.C.W. (2018a) STROBE software Github.

Chan, R.C.W. (2018b) STROBE fpga Github.

Chen, T.-W., Wardill, T.J., Sun, Y., Pulver, S.R., Renninger, S.L., Baohan, A., Schreiter, E.R., Kerr, R.A., Orger, M.B., Jayaraman, V., et al. (2013). Ultrasensitive fluorescent proteins for imaging neuronal activity. Nature 499, 295-300.

Chu, B., Chui, V., Mann, K., and Gordon, M.D. (2014). Presynaptic gain control drives sweet and bitter taste integration in Drosophila. Curr. Biol. 24, 1978-1984.

Clements, J., Dolafi, T., Umayam, L., Neubarth, N.L., Berg, S., Scheffer, L.K., and Plaza, S.M. (2020). neuPrint: Analysis Tools for EM Connectomics. bioRxiv.

Cully, D.F., Paress, P.S., Liu, K.K., Schaeffer, J.M., and Arena, J.P. (1996). Identification of a Drosophila melanogaster glutamate-gated chloride channel sensitive to the antiparasitic agent avermectin. J. Biol. Chem. 271, 20187-20191.

Currier, T.A., Matheson, A.M., and Nagel, K.I. (2020). Encoding and control of orientation to airflow by a set of Drosophila fan-shaped body neurons. Elife 9, 3074.

Dahanukar, A., Foster, K., van der Goes van Naters, W.M., and Carlson, J.R. (2001). A Gr receptor is required for response to the sugar trehalose in taste neurons of Drosophila. Nat. Neurosci. 4, 1182-1186.

Dahanukar, A., Lei, Y.-T., Kwon, J.Y., and Carlson, J.R. (2007). Two Gr genes underlie sugar reception in Drosophila. Neuron 56, 503-516.

Donlea, J.M., Thimgan, M.S., Suzuki, Y., Gottschalk, L., and Shaw, P.J. (2011). Inducing sleep by remote control facilitates memory consolidation in Drosophila. Science 332, 1571-1576.

Dus, M., Ai, M., and Suh, G.S.B. (2013). Taste-independent nutrient selection is mediated by a brainspecific $\mathrm{Na}+$ /solute co-transporter in Drosophila. Nat. Neurosci. 16, 526-528.

Dus, M., Lai, J.S.-Y., Gunapala, K.M., Min, S., Tayler, T.D., Hergarden, A.C., Geraud, E., Joseph, C.M., and Suh, G.S.B. (2015). Nutrient Sensor in the Brain Directs the Action of the Brain-Gut Axis in Drosophila. Neuron.

Dus, M., Min, S., Keene, A.C., Lee, G.Y., and Suh, G.S.B. (2011). Taste-independent detection of the caloric content of sugar in Drosophila. Proc. Natl. Acad. Sci. U.S.a. 108, 11644-11649. 
Escher, S.A., and Rasmuson-Lestander, A. (1999). The Drosophila glucose transporter gene: cDNA sequence, phylogenetic comparisons, analysis of functional sites and secondary structures. Hereditas $130,95-103$.

Eschment, M., Franz, H.R., Güllü, N., Hölscher, L.G., Huh, K.-E., and Widmann, A. (2020). Insulin signaling represents a gating mechanism between different memory phases in Drosophila larvae. PLoS Genet. 16, e1009064.

Fisher, Y.E., Lu, J., D'Alessandro, I., and Wilson, R.I. (2019). Sensorimotor experience remaps visual input to a heading-direction network. Nature 576, 121-125.

Gordon, M.D., and Scott, K. (2009). Motor control in a Drosophila taste circuit. Neuron 61, 373-384.

Hamada, F.N., Rosenzweig, M., Kang, K., Pulver, S.R., Ghezzi, A., Jegla, T.J., and Garrity, P.A. (2008). An internal thermal sensor controlling temperature preference in Drosophila. Nature 454, 217-220.

Honkanen, A., Adden, A., da Silva Freitas, J., and Heinze, S. (2019). The insect central complex and the neural basis of navigational strategies. J. Exp. Biol. 222, jeb188854.

Hu, W., Peng, Y., Sun, J., Zhang, F., Zhang, X., Wang, L., Li, Q., and Zhong, Y. (2018). Fan-Shaped Body Neurons in the Drosophila Brain Regulate Both Innate and Conditioned Nociceptive Avoidance. Cell Rep 24, 1573-1584.

Hulse, B.K., Haberkern, H., Franconville, R., Turner-Evans, D.B., Takemura, S., Wolff, T., Noorman, M., Dreher, M., Dan, C., Parekh, R., et al. (2020). A connectome of the Drosophila central complex reveals network motifs suitable for flexible navigation and context-dependent action selection. bioRxiv.

Ignell, R., Root, C.M., Birse, R.T., Wang, J.W., Nässel, D.R., and Winther, A.M.E. (2009). Presynaptic peptidergic modulation of olfactory receptor neurons in Drosophila. Proc. Natl. Acad. Sci. U.S.a. 106, 13070-13075.

Im, S.H., Takle, K., Jo, J., Babcock, D.T., Ma, Z., Xiang, Y., and Galko, M.J. (2015). Tachykinin acts upstream of autocrine Hedgehog signaling during nociceptive sensitization in Drosophila. Elife 4, e10735.

Inagaki, H.K., Ben-Tabou de-Leon, S., Wong, A.M., Jagadish, S., Ishimoto, H., Barnea, G., Kitamoto, T., Axel, R., and Anderson, D.J. (2012). Visualizing neuromodulation in vivo: TANGO-mapping of dopamine signaling reveals appetite control of sugar sensing. Cell 148, 583-595.

Inagaki, H.K., Panse, K.M., and Anderson, D.J. (2014). Independent, reciprocal neuromodulatory control of sweet and bitter taste sensitivity during starvation in Drosophila. Neuron 84, 806-820.

Itskov, P.M., Moreira, J.-M., Vinnik, E., Lopes, G., Safarik, S., Dickinson, M.H., and Ribeiro, C. (2014). Automated monitoring and quantitative analysis of feeding behaviour in Drosophila. Nat Commun 5 , 4560 .

Jaeger, A.H., Stanley, M., Weiss, Z.F., Musso, P.-Y., Chan, R.C., Zhang, H., Feldman-Kiss, D., and Gordon, M.D. (2018). A complex peripheral code for salt taste in Drosophila. Elife 7, 44.

Jenett, A., Rubin, G.M., Ngo, T.-T.B., Shepherd, D., Murphy, C., Dionne, H., Pfeiffer, B.D., Cavallaro, A., Hall, D., Jeter, J., et al. (2012). A GAL4-driver line resource for Drosophila neurobiology. Cell Rep 2, 9911001.

Jiao, Y., Moon, S.J., Wang, X., Ren, Q., and Montell, C. (2008). Gr64f is required in combination with 
other gustatory receptors for sugar detection in Drosophila. Curr. Biol. 18, 1797-1801.

Kahsai, L., Carlsson, M.A., Winther, A.M.E., and Nässel, D.R. (2012). Distribution of metabotropic receptors of serotonin, dopamine, GABA, glutamate, and short neuropeptide $\mathrm{F}$ in the central complex of Drosophila. Neuroscience 208, 11-26.

Kahsai, L., and Winther, A.M.E. (2011). Chemical neuroanatomy of the Drosophila central complex: distribution of multiple neuropeptides in relation to neurotransmitters. J. Comp. Neurol. 519, $290-315$.

Kain, P., and Dahanukar, A. (2015). Secondary taste neurons that convey sweet taste and starvation in the Drosophila brain. Neuron 85, 819-832.

Kapan, N., Lushchak, O.V., Luo, J., and Nässel, D.R. (2012). Identified peptidergic neurons in the Drosophila brain regulate insulin-producing cells, stress responses and metabolism by coexpressed short neuropeptide F and corazonin. Cell. Mol. Life Sci. 69, 4051-4066.

Klapoetke, N.C., Murata, Y., Kim, S.S., Pulver, S.R., Birdsey-Benson, A., Cho, Y.K., Morimoto, T.K., Chuong, A.S., Carpenter, E.J., Tian, Z., et al. (2014). Independent optical excitation of distinct neural populations. Nat. Methods 11, 338-346.

Ko, K.I., Root, C.M., Lindsay, S.A., Zaninovich, O.A., Shepherd, A.K., Wasserman, S.A., Kim, S.M., and Wang, J.W. (2015). Starvation promotes concerted modulation of appetitive olfactory behavior via parallel neuromodulatory circuits. Elife 4, 691.

Kondo, S., Takahashi, T., Yamagata, N., Imanishi, Y., Katow, H., Hiramatsu, S., Lynn, K., Abe, A., Kumaraswamy, A., and Tanimoto, H. (2020). Neurochemical Organization of the Drosophila Brain Visualized by Endogenously Tagged Neurotransmitter Receptors. Cell Rep 30, 284-297.e285.

Kwon, J.Y., Dahanukar, A., Weiss, L.A., and Carlson, J.R. (2014). A map of taste neuron projections in the Drosophila CNS. J. Biosci. 39, 565-574.

LeDue, E.E., Chen, Y.-C., Jung, A.Y., Dahanukar, A., and Gordon, M.D. (2015). Pharyngeal sense organs drive robust sugar consumption in Drosophila. Nat Commun 6, 6667.

LeDue, E.E., Mann, K., Koch, E., Chu, B., Dakin, R., and Gordon, M.D. (2016). Starvation-Induced Depotentiation of Bitter Taste in Drosophila. Curr. Biol. 26, 2854-2861.

Lénárd, L., László, K., Kertes, E., Ollmann, T., Péczely, L., Kovács, A., Kállai, V., Zagorácz, O., Gálosi, R., and Karádi, Z. (2018). Substance $P$ and neurotensin in the limbic system: Their roles in reinforcement and memory consolidation. Neurosci Biobehav Rev 85, 1-20.

Li, W., Pan, Y., Wang, Z., Gong, H., Gong, Z., and Liu, L. (2009). Morphological characterization of single fan-shaped body neurons in Drosophila melanogaster. Cell Tissue Res. 336, 509-519.

Li, X.J., Wolfgang, W., Wu, Y.N., North, R.A., and Forte, M. (1991). Cloning, heterologous expression and developmental regulation of a Drosophila receptor for tachykinin-like peptides. Embo J 10, 3221-3229.

Lin, S., Senapati, B., and Tsao, C.-H. (2019). Neural basis of hunger-driven behaviour in Drosophila. Open Biol 9, 180259.

Liu, C., Plaçais, P.-Y., Yamagata, N., Pfeiffer, B.D., Aso, Y., Friedrich, A.B., Siwanowicz, I., Rubin, G.M., Preat, T., and Tanimoto, H. (2012). A subset of dopamine neurons signals reward for odour memory in Drosophila. Nature 488, 512-516. 
Liu, G., Seiler, H., Wen, A., Zars, T., Ito, K., Wolf, R., Heisenberg, M., and Liu, L. (2006). Distinct memory traces for two visual features in the Drosophila brain. Nature 439, 551-556.

Liu, S., Liu, Q., Tabuchi, M., and Wu, M.N. (2016). Sleep Drive Is Encoded by Neural Plastic Changes in a Dedicated Circuit. Cell 165, 1347-1360.

Marella, S., Fischler, W., Kong, P., Asgarian, S., Rueckert, E., and Scott, K. (2006). Imaging taste responses in the fly brain reveals a functional map of taste category and behavior. Neuron 49, $285-295$.

McGuire, S.E., Mao, Z., and Davis, R.L. (2004). Spatiotemporal gene expression targeting with the TARGET and gene-switch systems in Drosophila. Sci. STKE 2004, pl6-pl6.

Merino, B., Fernández-Díaz, C.M., Cózar-Castellano, I., and Perdomo, G. (2019). Intestinal Fructose and Glucose Metabolism in Health and Disease. Nutrients 12, 94.

Mery, F., and Kawecki, T.J. (2005). A cost of long-term memory in Drosophila. Science 308, 1148-1148.

Minokoshi, Y., Alquier, T., Furukawa, N., Kim, Y.-B., Lee, A., Xue, B., Mu, J., Foufelle, F., Ferré, P., Birnbaum, M.J., et al. (2004). AMP-kinase regulates food intake by responding to hormonal and nutrient signals in the hypothalamus. Nature $428,569-574$.

Miyamoto, T., Slone, J., Song, X., and Amrein, H. (2012). A fructose receptor functions as a nutrient sensor in the Drosophila brain. Cell 151, 1113-1125.

Molina-Obando, S., Vargas-Fique, J.F., Henning, M., Gür, B., Schladt, T.M., Akhtar, J., Berger, T.K., and Silies, M. (2019). ON selectivity in the Drosophila visual system is a multisynaptic process involving both glutamatergic and GABAergic inhibition. Elife 8, 2247.

Monnier, D., Colas, J.F., Rosay, P., Hen, R., Borrelli, E., and Maroteaux, L. (1992). NKD, a developmentally regulated tachykinin receptor in Drosophila. J. Biol. Chem. 267, 1298-1302.

Moser, D., Johnson, L., and Lee, C.Y. (1980). Multiple forms of Drosophila hexokinase. Purification, biochemical and immunological characterization. J. Biol. Chem. 255, 4673-4679.

Musso, P.-Y., Junca, P., Jelen, M., Feldman-Kiss, D., Zhang, H., Chan, R.C., and Gordon, M.D. (2019). Closed-loop optogenetic activation of peripheral or central neurons modulates feeding in freely moving Drosophila. Elife 8, 1445.

Musso, P.-Y., Lampin-Saint-Amaux, A., Tchenio, P., and Preat, T. (2017). Ingestion of artificial sweeteners leads to caloric frustration memory in Drosophila. Nat Commun 8, 1803.

Musso, P.-Y., Tchenio, P., and Preat, T. (2015). Delayed dopamine signaling of energy level builds appetitive long-term memory in Drosophila. Cell Rep 10, 1023-1031.

Nässel, D.R., Zandawala, M., Kawada, T., and Satake, H. (2019). Tachykinins: Neuropeptides That Are Ancient, Diverse, Widespread and Functionally Pleiotropic. Front Neurosci 13, 1262.

Niwano, Y., Adachi, T., Kashimura, J., Sakata, T., Sasaki, H., Sekine, K., Yamamoto, S., Yonekubo, A., and Kimura, S. (2009). Is glycemic index of food a feasible predictor of appetite, hunger, and satiety? J Nutr Sci Vitaminol (Tokyo) 55, 201-207.

Oh, Y., Lai, J.S.-Y., Mills, H.J., Erdjument-Bromage, H., Giammarinaro, B., Saadipour, K., Wang, J.G., Abu, F., Neubert, T.A., and Suh, G.S.B. (2019). A glucose-sensing neuron pair regulates insulin and 
glucagon in Drosophila. Nature 574, 559-564.

Park, J.-H., and Kwon, J.Y. (2011). A systematic analysis of Drosophila gustatory receptor gene expression in abdominal neurons which project to the central nervous system. Mol. Cells 32, 375-381.

Pascual, A., Huang, K.-L., Neveu, J., and Preat, T. (2004). Neuroanatomy: brain asymmetry and longterm memory. Nature 427, 605-606.

Pfeiffer, K., and Homberg, U. (2014). Organization and functional roles of the central complex in the insect brain. Annu. Rev. Entomol. 59, 165-184.

Plaçais, P.-Y., Balland, M., Guérin, T., Joanny, J.-F., and Martin, P. (2009). Spontaneous oscillations of a minimal actomyosin system under elastic loading. Phys Rev Lett 103, 158102.

Plaçais, P.-Y., and Preat, T. (2013). To favor survival under food shortage, the brain disables costly memory. Science 339, 440-442.

Plaçais, P.-Y., de Tredern, É., Scheunemann, L., Trannoy, S., Goguel, V., Han, K.-A., Isabel, G., and Preat, T. (2017). Upregulated energy metabolism in the Drosophila mushroom body is the trigger for longterm memory. Nat Commun 8, 15510.

Plaçais, P.-Y., Trannoy, S., Isabel, G., Aso, Y., Siwanowicz, I., Belliart-Guérin, G., Vernier, P., Birman, S., Tanimoto, H., and Preat, T. (2012). Slow oscillations in two pairs of dopaminergic neurons gate long-term memory formation in Drosophila. Nat. Neurosci. 15, 592-599.

Poels, J., Birse, R.T., Nachman, R.J., Fichna, J., Janecka, A., Vanden Broeck, J., and Nässel, D.R. (2009). Characterization and distribution of NKD, a receptor for Drosophila tachykinin-related peptide 6. Peptides 30, 545-556.

Qi, W., Wang, G., and Wang, L. (2020). A novel satiety sensor detects circulating glucose and suppresses food consumption via insulin-producing cells in Drosophila. Cell Res 19, 206-209.

Root, C.M., Ko, K.I., Jafari, A., and Wang, J.W. (2011). Presynaptic facilitation by neuropeptide signaling mediates odor-driven food search. Cell 145, 133-144.

Rovenko, B.M., Kubrak, O.I., Gospodaryov, D.V., Perkhulyn, N.V., Yurkevych, I.S., Sanz, A., Lushchak, O.V., and Lushchak, V.I. (2015a). High sucrose consumption promotes obesity whereas its low consumption induces oxidative stress in Drosophila melanogaster. J. Insect Physiol. 79, 42-54.

Rovenko, B.M., Perkhulyn, N.V., Gospodaryov, D.V., Sanz, A., Lushchak, O.V., and Lushchak, V.I. (2015b). High consumption of fructose rather than glucose promotes a diet-induced obese phenotype in Drosophila melanogaster. Comp. Biochem. Physiol., Part a Mol. Integr. Physiol. 180, 75-85.

Sakai, T., and Kitamoto, T. (2006). Differential roles of two major brain structures, mushroom bodies and central complex, for Drosophila male courtship behavior. J Neurobiol 66, 821-834.

Sayin, S., De Backer, J.-F., Siju, K.P., Wosniack, M.E., Lewis, L.P., Frisch, L.-M., Gansen, B., Schlegel, P., Edmondson-Stait, A., Sharifi, N., et al. (2019). A Neural Circuit Arbitrates between Persistence and Withdrawal in Hungry Drosophila. Neuron 104, 544-558.e546.

Scheunemann, L., Plaçais, P.-Y., Dromard, Y., Schwärzel, M., and Preat, T. (2018). Dunce Phosphodiesterase Acts as a Checkpoint for Drosophila Long-Term Memory in a Pair of Serotonergic Neurons. Neuron 98, 350-365.e355. 
Schindelin, J., Arganda-Carreras, I., Frise, E., Kaynig, V., Longair, M., Pietzsch, T., Preibisch, S., Rueden, C., Saalfeld, S., Schmid, B., et al. (2012). Fiji: an open-source platform for biological-image analysis. Nat. Methods 9, 676-682.

Scott, K. (2018). Gustatory Processing in Drosophila melanogaster. Annu. Rev. Entomol. 63, 15-30.

Slankster, E., Kollala, S., Baria, D., Dailey-Krempel, B., Jain, R., Odell, S.R., and Mathew, D. (2020). Mechanism underlying starvation-dependent modulation of olfactory behavior in Drosophila larva. Sci Rep 10, 3119-14.

Song, W., Veenstra, J.A., and Perrimon, N. (2014). Control of lipid metabolism by tachykinin in Drosophila. Cell Rep 9, 40-47.

Strauss, R. (2002). The central complex and the genetic dissection of locomotor behaviour. Curr. Opin. Neurobiol. 12, 633-638.

Sun, X., Yue, S., and Mangan, M. (2020). A decentralised neural model explaining optimal integration of navigational strategies in insects. Elife 9, 219.

Takeuchi, H., Yasuda, A., Yasuda-Kamatani, Y., Sawata, M., Matsuo, Y., Kato, A., Tsujimoto, A., Nakajima, T., and Kubo, T. (2004). Prepro-tachykinin gene expression in the brain of the honeybee Apis mellifera. Cell Tissue Res. 316, 281-293.

Talay, M., Richman, E.B., Snell, N.J., Hartmann, G.G., Fisher, J.D., Sorkaç, A., Santoyo, J.F., ChouFreed, C., Nair, N., Johnson, M., et al. (2017). Transsynaptic Mapping of Second-Order Taste Neurons in Flies by trans-Tango. Neuron 96, 783-795.e784.

Thorne, N., Chromey, C., Bray, S., and Amrein, H. (2004). Taste perception and coding in Drosophila. Curr. Biol. 14, 1065-1079.

Thorner, M.O., Holl, R.W., and Leong, D.A. (1988). The somatotrope: an endocrine cell with functional calcium transients. J. Exp. Biol. 139, 169-179.

Ueno, T., Tomita, J., Tanimoto, H., Endo, K., Ito, K., Kume, S., and Kume, K. (2012). Identification of a dopamine pathway that regulates sleep and arousal in Drosophila. Nat. Neurosci. 15, 1516-1523.

Volkenhoff, A., Hirrlinger, J., Kappel, J.M., Klämbt, C., and Schirmeier, S. (2018). Live imaging using a FRET glucose sensor reveals glucose delivery to all cell types in the Drosophila brain. J. Insect Physiol. 106, 55-64.

Wang, J.W., Wong, A.M., Flores, J., Vosshall, L.B., and Axel, R. (2003). Two-photon calcium imaging reveals an odor-evoked map of activity in the fly brain. Cell 112, 271-282.

Wang, R., Liu, X., Hentges, S.T., Dunn-Meynell, A.A., Levin, B.E., Wang, W., and Routh, V.H. (2004a). The regulation of glucose-excited neurons in the hypothalamic arcuate nucleus by glucose and feedingrelevant peptides. Diabetes 53, 1959-1965.

Wang, Z., Pan, Y., Li, W., Jiang, H., Chatzimanolis, L., Chang, J., Gong, Z., and Liu, L. (2008). Visual pattern memory requires foraging function in the central complex of Drosophila. Learn. Mem. 15, 133142.

Wang, Z., Singhvi, A., Kong, P., and Scott, K. (2004b). Taste representations in the Drosophila brain. Cell 117, 981-991. 
Weir, P.T., and Dickinson, M.H. (2015). Functional divisions for visual processing in the central brain of flying Drosophila. Proc. Natl. Acad. Sci. U.S.a. 112, E5523-E5532.

Winther, A.M.E., Siviter, R.J., Isaac, R.E., Predel, R., and Nässel, D.R. (2003). Neuronal expression of tachykinin-related peptides and gene transcript during postembryonic development of Drosophila. J. Comp. Neurol. 464, 180-196.

Wolff, T., and Rubin, G.M. (2018). Neuroarchitecture of the Drosophila central complex: A catalog of nodulus and asymmetrical body neurons and a revision of the protocerebral bridge catalog. J. Comp. Neurol. 526, 2585-2611.

Wolff, T., lyer, N.A., and Rubin, G.M. (2015). Neuroarchitecture and neuroanatomy of the Drosophila central complex: A GAL4-based dissection of protocerebral bridge neurons and circuits. J. Comp. Neurol. 523, 997-1037.

Yapici, N., Cohn, R., Schusterreiter, C., Ruta, V., and Vosshall, L.B. (2016). A Taste Circuit that Regulates Ingestion by Integrating Food and Hunger Signals. Cell.

\section{KEY RESSOURCES TABLE}

\begin{tabular}{|c|c|c|}
\hline REAGENT or RESSOURCE & SOURCE & IDENTIFIER \\
\hline \multicolumn{3}{|l|}{ Antibodies } \\
\hline Rabbit anti-GFP & Invitrogen & A11122 \\
\hline Rabbit anti-DsRed & Clontech & 632496 \\
\hline Rabbit anti-RFP & Rockland & $600-401-379$ \\
\hline Mouse anti-brp & DSHB & Nc82 \\
\hline Mouse anti-GFP & Sigma & G6539 \\
\hline Rat anti-HA & Roche & 1867423001 \\
\hline Chicken anti-GFP & Abcam & 13970 \\
\hline Goat anti-rabbit Alexa 488 & Invitrogen & A11008 \\
\hline Goat anti-mouse Alexa 488 & Invitrogen & A11029 \\
\hline Goat anti-mouse Alexa 568 & Invitrogen & $\mathrm{A} 11030$ \\
\hline Goat anti-rabbit 647 & Thermo Fisher Scientific & A21245 \\
\hline \multicolumn{3}{|l|}{ Goat anti-rat 647} \\
\hline $\begin{array}{ll}\text { Goat } & \text { anti-chicken } \\
\text { Alexa } 488 & \end{array}$ & Abcam & 150169 \\
\hline \multicolumn{3}{|l|}{$\begin{array}{l}\text { Chemicals, Peptides, and Recombinant } \\
\text { Proteins }\end{array}$} \\
\hline Sucrose & Sigma-Aldrich & S7903 \\
\hline L-glucose & Sigma-Aldrich & G5500 \\
\hline D-sorbitol & Sigma-Aldrich & S1876 \\
\hline D-glucose & Sigma-Aldrich & G8270 \\
\hline Fructose & Sigma-Aldrich & F0127 \\
\hline All-trans-retinal & Sigma-Aldrich & $\mathrm{R} 2500$ \\
\hline Agar & Sigma-Aldrich & A1296 \\
\hline 4\% Paraformaldehydein PBS & Alfa Aesar & J61899 \\
\hline Erioglaucine, FD\&C Blue \#1 & Spectrum & FD110 \\
\hline Amaranth FD\&C Red \#2 & Sigma-Aldrich & A1016 \\
\hline \multicolumn{3}{|l|}{ Experimental Models: Organisms/Strains } \\
\hline $\begin{array}{lcc}\text { Drosophila, } & w[1118] ; & P\{y[+t 7.7] \\
w[+m C]=G M R 70 H 05-G A L 4\} \text { attP2 } & \\
\end{array}$ & $\begin{array}{l}\text { Bloomington; (Jenett et al., } \\
\text { 2012) }\end{array}$ & BDSC_39554 \\
\hline $\begin{array}{lcc}\text { Drosophila, } & \mathrm{w}[1118] ; & \mathrm{P}\{\mathrm{y}[+\mathrm{t} 7.7] \\
\mathrm{w}[+\mathrm{mC}]=\mathrm{GMR} 70 \mathrm{H} \text { 05-lexA }\} \text { attP40/CyO } & \\
\end{array}$ & $\begin{array}{l}\text { Bloomington; (Jenett et al., } \\
\text { 2012) }\end{array}$ & BDSC_54255 \\
\hline $\begin{array}{lcc}\text { Drosophila, } & \mathrm{w}[1118] ; & \mathrm{P}\{\mathrm{y}[+\mathrm{t} 7.7] \\
\mathrm{w}[+\mathrm{mC}]=\mathrm{GMR} 72 \mathrm{~A} 10-\mathrm{GAL} 4\} \text { attP2/TM3, } & \mathrm{Sb}[1]\end{array}$ & $\begin{array}{l}\text { Bloomington; (Jenett et al., } \\
\text { 2012) }\end{array}$ & BDSC_48306 \\
\hline $\begin{array}{lcc}\text { Drosophila, } & \mathrm{w}[1118] ; & \mathrm{P}\{\mathrm{y}[+\mathrm{t} 7.7] \\
\mathrm{w}[+\mathrm{mC}]=\mathrm{GMR} 72 \mathrm{~A} 10-\mathrm{lexA}\} \mathrm{attP} 40 & \\
\end{array}$ & $\begin{array}{l}\text { Bloomington; (Jenett et al., } \\
\text { 2012) }\end{array}$ & BDSC_54191 \\
\hline VT005528-GAL4 & VDRC & $\mathrm{N} / \mathrm{A}$ \\
\hline
\end{tabular}


bioRxiv preprint doi: https://doi.org/10.1101/2021.04.08.439043; this version posted April 9, 2021. The copyright holder for this preprint (which was not certified by peer review) is the author/funder, who has granted bioRxiv a license to display the preprint in perpetuity. It is made available under aCC-BY-NC 4.0 International license.

\begin{tabular}{|c|c|c|}
\hline FB split-GAL4 (VT038216.P65; VT017124.DBD) & This paper & $\mathrm{N} / \mathrm{A}$ \\
\hline AB-SLP split-GAL4 (R72A10.P65; R37G11.DBD) & This paper & $\mathrm{N} / \mathrm{A}$ \\
\hline Gr43aGAL4 (knock-in) & $\begin{array}{l}\text { Amrein lab; (Miyamoto et } \\
\text { al., 2012) }\end{array}$ & $\mathrm{N} / \mathrm{A}$ \\
\hline Gr43a-GAL4,Cha ${ }^{7.4 k b-G A L 80 / T m 6 b ~}$ & $\begin{array}{l}\text { Amrein lab; (Miyamoto et } \\
\text { al., 2012) }\end{array}$ & $\mathrm{N} / \mathrm{A}$ \\
\hline $\begin{array}{l}\text { Drosophila, w[1118]; P }\{\mathrm{y}[+\mathrm{t} 7.7] \mathrm{w}[+\mathrm{mC}]=20 X U A S- \\
\text { IVS-GCaMP6f\}attP40 }\end{array}$ & Bloomington & BDSC_42747 \\
\hline $\begin{array}{l}\text { Drosophila, w[*]; P\{y[+t7.7] w[+mC]=40XUAS- } \\
\text { IVS-mCD8::GFP }\} \text { attP2 }\end{array}$ & Bloomington & BDSC_32195 \\
\hline 26XLexAop2-mCD8::GFP & Bloomington & BDSC_52265 \\
\hline $\begin{array}{l}\text { Drosophila, y[1] w[*] P\{y[+t7.7] w[+mC]=UAS- } \\
\text { myrGFP.QUAS-mtdTomato-3xHA\}su(Hw)attP8; } \\
\text { P\{y[+t7.7] w[+mC]=trans-Tango\}attP40 }\end{array}$ & $\begin{array}{l}\text { Bloomington; (Talay et al., } \\
\text { 2017) }\end{array}$ & BDSC_77124 \\
\hline $\begin{array}{l}\text { UAS-CD4::spGFP1-10 and LexAop- } \\
\text { CD4::spGFP11 }\end{array}$ & (Gordon and Scott, 2009) & \\
\hline $\begin{array}{l}\text { Drosophila, w[1118]; L[1]/CyO; } \mathrm{P}\{\mathrm{w}[+\mathrm{mC}]=\mathrm{UAS}- \\
\text { DenMark }\}, \mathrm{P}\{\mathrm{w}[+\mathrm{mC}]=U A S-s y t . e G F P\} 3\end{array}$ & Bloomington & BDSC_33065 \\
\hline $\begin{array}{l}\text { Drosophila, w[1118]; } \mathrm{P}\{\mathrm{y}[+\mathrm{t} 7.7] \mathrm{w}[+\mathrm{mC}]=20 X U A S- \\
\text { IVS-CsChrimson.mVenus }\} \text { attP } 40\end{array}$ & Bloomington & BDSC_55136 \\
\hline $\begin{array}{l}\text { Drosophila, y[1] sc[*] v[1] sev[21]; } \mathrm{P}\{\mathrm{y}[+\mathrm{t} 7.7] \\
\mathrm{v}[+\mathrm{t} 1.8]=\mathrm{TR} \text { iP.HMS02152\}attP40 }\end{array}$ & Bloomington & BDSC_40904 \\
\hline $\begin{array}{l}\text { Drosophila, y[1] } \quad \text { sc[*] v[1] } \operatorname{sev[21];} \mathrm{P}\{\mathrm{y}[+\mathrm{t} 7.7] \\
\text { v[+t1.8]=TRiP.HMC04708\}attP40 }\end{array}$ & Bloomington & BDSC_57404 \\
\hline 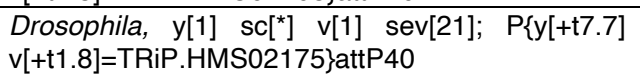 & Bloomington & BDSC_40927 \\
\hline $\begin{array}{lrr}\text { Drosophila,y[1] } & \mathrm{v}[1] ; & \mathrm{P}\{\mathrm{y}[+\mathrm{t} 7.7] \\
\mathrm{v}[+\mathrm{t} 1.8]=\text { RRiP.JF02689\}attP2 } & \\
\end{array}$ & Bloomington & BDSC_27538 \\
\hline $\begin{array}{l}\text { Drosophila, y[1] sc[*] v[1] sev[21]; } \mathrm{P}\{\mathrm{y}[+\mathrm{t} 7.7] \\
\mathrm{v}[+\mathrm{t} 1.8]=\text { TRiP.HMC03585\}attP40 }\end{array}$ & Bloomington & BDSC_53356 \\
\hline 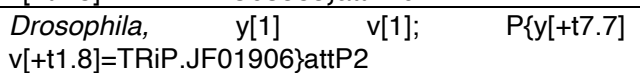 & Bloomington & BDSC_25867 \\
\hline $\begin{array}{lcc}\text { Drosophila, } \quad[1] \quad v[1] ; & \mathrm{P}\{\mathrm{y}[+\mathrm{t} 7.7] \\
\text { v[+t1.8]=TRiP.JF01818\}attP2 }\end{array}$ & Bloomington & BDSC_25800 \\
\hline $\begin{array}{lcc}\text { Drosophila, } y[1] & \mathrm{v}[1] ; & \mathrm{P}\{\mathrm{y}[+\mathrm{t} 7.7] \\
\mathrm{v}[+\mathrm{t} 1.8]=\text { TRRiP.JF02160\}attP2 }\end{array}$ & Bloomington & BDSC_31884 \\
\hline $\begin{array}{lcc}\text { Drosophila, y[1] v[1]; } & \mathrm{P}\{\mathrm{y}[+\mathrm{t} 7.7] \\
\mathrm{v}[+\mathrm{t} 1.8]=\text { TRiP.JF02663\}attP2 }\end{array}$ & Bloomington & BDSC_27513 \\
\hline $\begin{array}{l}\text { Drosophila, y[1] sc[*] v[1] sev[21]; } \mathrm{P}\{\mathrm{y}[+\mathrm{t} 7.7] \\
\mathrm{v}[+\mathrm{t} 1.8]=\text { TRiP.HMS02011\}attP2 }\end{array}$ & Bloomington; & BDSC_40845 \\
\hline UAS-Kir2.1 & (Baines et al., 2001) & Flybase:FBti0017552 \\
\hline Tubulin-GAL80ts & (McGuire et al., 2004) & Flybase:FBti0027797 \\
\hline LexAop2-TNT & $\begin{array}{l}\text { from Mark N. Wu lab, (Liu } \\
\text { et al., 2016) }\end{array}$ & \\
\hline UAS-dTrPA1 & (Hamada et al., 2008) & BDSC_26263 \\
\hline \multicolumn{3}{|l|}{ Softwares and Algorithms } \\
\hline FIJI & (Schindelin et al., 2012) & https://imagej.net/Fiji \\
\hline MATLAB & $\begin{array}{l}\text { The Mathworks Inc., Natick, } \\
\text { MA }\end{array}$ & https://fr.mathworks.com/ \\
\hline Prism 6 & Graphpad & RRID: SCR_002798 \\
\hline Illustrator & Adobe & RRID: SCR_010279 \\
\hline $\begin{array}{l}\text { STROBE } \\
\text { executable }\end{array}$ & Chan, 2018a & $\begin{array}{l}\text { github: } \\
\text { https://github.com/rcwchan/STROBE_software/ (c } \\
\text { opy archived at https://github.com/elifesciences- } \\
\text { publications/STROBE_software) }\end{array}$ \\
\hline $\begin{array}{l}\text { STROBE } \\
\text { processing }\end{array}$ & Chan, 2018a & $\begin{array}{l}\text { github: } \\
\text { https://github.com/rcwchan/STROBE_software/ } \\
\text { (copy archived at https://github.com/elifesciences- } \\
\text { publications/STROBE_software) }\end{array}$ \\
\hline STROBE VHDL code & Chan, 2018b & $\begin{array}{l}\text { github: https://github.com/rcwchan/STROBE-fpga } \\
\text { (copy archived at https://github.com/elifesciences- } \\
\text { publications/STROBE-fpga) }\end{array}$ \\
\hline
\end{tabular}




\section{RESOURCE AVAILABILITY}

\section{Lead Contact}

Further information and requests for resources and reagents should be directed to and will be fulfilled by the Lead Contact, Dr Micheal D. Gordon (gordon@zoology.ubc.ca).

There are no restrictions on reagent sharing to disclose

Materials Availability

Flies generated in this study are available upon request.

Data and Code Availability

All STROBE software is available for download from Github:

FPGA code: https:/github.com/rcwchan/STROBE-fpga (copy archived at https://github.com/elifesciences-publications/STROBE-fpga).

All other code: https:/github.com/rcwchan/STROBE_software/ (copy archived at https://github.com/elifesciences-publications/STROBE_software).

\section{EXPERIMENTAL MODEL AND SUBJECT DETAILS}

\section{Drosophila melanogaster}

Fly stocks were raised on standard food at $25^{\circ} \mathrm{C}$ and $70 \%$ relative humidity under a $12: 12 \mathrm{hr}$ light:dark cycle. For neuronal silencing experiments we used UAS-Kir2.1 (Baines et al., 2001), tub-Gal80"s (McGuire et al., 2004), and LexAop-tnt (Liu et al., 2016). For neuronal activation experiments we used UAS-dTrpA1 (Hamada et al., 2008) and 20XUAS-IVSCsChrimson.mVenus (Bloomington \#55135). Specific FB expression was driven using R7OHO5GAL4 ((Jenett et al., 2012); Bloomington \#39554), R7OH05-LexA ((Jenett et al., 2012); Bloomington \#54255), VT005528-GAL4 (VDRC) and a newly built split-Gal4 line (VT038216.P65; VT017124.DBD). Specific SLP-AB expression was driven using R72A10-GAL4 ((Jenett et al., 2012); Bloomington \#48306), R72A10-LexA ((Jenett et al., 2012); Bloomington \#54191) and a newly built split-GAL4 line (R72A10.P65; R37G11.DBD). Specific Gr43a expression was driven using Gr43aGAL4 (knock-in) and Gr43aGal4,Cha7.4kb-GAL80 ((Miyamoto et al., 2012); gift from $\mathrm{H}$. Amrein). For staining experiments, we used 40XUAS-IVS-mCD8::GFP (Bloomington \#32195), 26XLexAop2-mCD8::GFP (Bloomington \#77124), Trans-Tango ((Talay et al., 2017); Bloomington \#77124), 20XUAS-IVS-CsChrimson (Bloomington \#55136), and UASDenMark,UAS-Syt (Nicola et al., 2010; Bloomington \#33065). For GRASP experiment, we used UAS-CD4::spGFP1-10 and LexAop-CD4::spGFP11 (Gordon and Scott, 2009). For imaging experiments we used the 20XUAS-IVS-GCaMP6f (Bloomington \#42747). For RNAi experiments, we used RNAi against Glut1 (Bloomington \#40904), HexC (Bloomington \#57404), Vglut (Bloomington \#40927), Vglut (Bloomington \#27538), Vglut (Bloomington \#40845) GluCla (Bloomington \#53356), sNPF (Bloomington v25867), Tk (Bloomington \#25800), TkR 99D (Bloomington \#27513), and TkR86C (Bloomington \#31884).

\section{METHOD DETAILS}

\section{Fly preparation and behavior experiments}

All experiments were performed with mated female flies to reduce variability, given that sex differences were not a subject of investigation. After eclosion, flies were kept for 2 to three days in fresh vials containing standard medium. For thermo-sensitive silencing experiments (Kirts), 
flies were then transferred into vials for 2 days at $29^{\circ} \mathrm{C}$. Flies were subjected to a varying fasting period (0-30 hrs) where they were transferred to vials containing $1 \mathrm{ml}$ of $1 \%$ agar at 29 ${ }^{\circ} \mathrm{C}$. For silencing (UAS-kir2.1; LexAop-tnt) and RNAi experiments, flies were transferred into vials containing $1 \mathrm{ml}$ of $1 \%$ agar at $29{ }^{\circ} \mathrm{C}$ for $15-18 \mathrm{hrs}$. For activation experiments (dTrpA1), flies were transferred into vials containing $1 \mathrm{ml}$ of $1 \%$ agar at $22{ }^{\circ} \mathrm{C}$ for $43-45 \mathrm{hrs}$. For STROBE experiments, flies were kept for several days in fresh vials containing standard medium, and were then transferred at $25^{\circ} \mathrm{C}$ into vials covered with aluminum foil containing $1 \mathrm{ml}$ standard medium (control flies) or $1 \mathrm{ml}$ standard medium containing with $1 \mathrm{mM}$ of all-trans-retinal (retinal flies) for 2 days. Flies were then subjected to a 24-hr fasting period where they were transferred to covered vials containing $1 \mathrm{ml}$ of $1 \%$ agar (control flies) or $1 \mathrm{ml}$ of $1 \%$ agar mixed with $1 \mathrm{mM}$ of all-trans-retinal (retinal flies). Sucrose, L-glucose, D-glucose, D-sorbitol, D-fructose and agar were obtained from Sigma-Aldrich.

\section{FlyPAD experiments}

All flies were 5-9 days old at the time of the assay, and experiments were performed between 10:00 am and 5:00 pm. For single tastant experiments, one channel of the arena was loaded with $3.5 \mu \mathrm{l}$ of $1 \%$ agar Mixed with a tastant. To exclude interactions due to drinking behavior, the other side was loaded with $3.5 \mu \mathrm{l}$ of $1 \%$ agar. The tastant used were sucrose $(5,50$ and 1000 $\mathrm{mM})$; L-glucose $(5,50$ and $1000 \mathrm{mM})$, L-glucose $50 \mathrm{mM}$ combined with D-sorbitol $(0,5,50,500$ and $1000 \mathrm{mM})$; D-glucose (5, 50 and $1000 \mathrm{mM})$; fructose (5, 50 and $1000 \mathrm{mM})$; and D-sorbitol $(50 \mathrm{mM})$. For dual tastant experiments, one channel was loaded with fructose while the other one with D-glucose, always in an equimolar manner (5, 50 and $1000 \mathrm{mM})$. Acquisition on the FlyPAD software was started and then single flies were transferred into each arena by mouth aspiration. Experiments were run for $60 \mathrm{~min}$, and the preference index for each fly was calculated as: (interactions with Food 1 - interactions with Food 2)/(interactions with Food $1+$ interactions with from Food 2). Tastants were all obtained from Sigma-Aldrich.

\section{STROBE experiments}

Experiments were performed as previously described (Jaeger et al., 2018; Musso et al., 2019). All flies were 5-9 days old at the time of the assay, and experiments were performed between 10:00 am and 5:00 pm. Both channels of the arena were loaded with $3.5 \mu \mathrm{l} \mathrm{of} 1 \%$ agar. Acquisition on the STROBE software was started and then single flies were transferred into each arena by mouth aspiration. Experiments were run for $60 \mathrm{~min}$, and the preference index for each fly was calculated as: (interactions with Food 1 - interactions with Food 2)/(interactions with Food $1+$ interactions with from Food 2). The red LED is always associated to the left side (Food 1), with a light intensity of $11.2 \mathrm{~mW} / \mathrm{cm}^{2}$. Agar and all-trans-retinal were obtained from Sigma-Aldrich.

\section{2-Choice}

Binary choice preference tests were similar to those previously described (Jaeger et al., 2018; LeDue et al., 2015). Female flies aged 2-5 days were sorted into groups of 10 and were transferred starved as explained above. For the assays, flies were then transferred into testing vials containing six $10 \mu \mathrm{L}$ dots of agar that alternated in color. The food choices were: $1 \%$ agar with $50 \mathrm{mM}$ fructose (Food 1), and 1\% agar with 50 D-glucose (Food 2). Each choice contained either $0.125 \mathrm{mg} / \mathrm{mL}$ blue (Erioglaucine, FD and C Blue\#1) or $0.5 \mathrm{mg} / \mathrm{mL}$ red (Amaranth, FD and C Red\#2) dye, and half the replicates for each experiment were done with the dyes swapped to control for any dye preference. Flies were allowed to feed for $2 \mathrm{hr}$ in the dark at $29^{\circ} \mathrm{C}$ and then frozen and scored for abdomen color. Preference index (PI) was calculated as ((\# of flies labeled with Food 1 color) - (\# of flies labeled with Food 2 color))/(total number of flies that fed). 


\section{PER}

For tarsal PER, flies were mounted on glass slides using nail polish. For labellar PER, flies were placed inside a pipette tip cut to size so that only the head was exposed. Flies were then sealed into the tube with tape, and then adhered to a glass slide with double-sided tape. Flies were allowed $1-2 \mathrm{~h}$ to recover before testing began. Flies were stimulated with water on their front tarsi or labella for tarsal and labellar PER, respectively, and allowed to drink until satiated. Each fly was then stimulated with increasing concentration of a either D-glucose or fructose on either the tarsi or labella, and responses to each tastant were recorded. Flies were provided with water between each tastant. All stimuli were delivered with a $1 \mathrm{ml}$ syringe attached to a $20 \mu \mathrm{l}$ pipette tip.

\section{In-Vivo Calcium imaging}

Female flies aged 5-9 days were briefly anesthetized. With a custom chamber, each fly was mounted by insertion of the cervix into individual collars. For further immobilization of the head, nail polish was applied in a thin layer to seal the head to the chamber. The antennae and the associated cuticle covering the SEZ were removed until the ocelli, and adult hemolymph-like (AHL) buffer with ribose (Liu et al., 2012; Wang et al., 2003) was immediately injected into the preparation to cover the exposed brain. Flies were left to recover from anesthesia for an hour before imaging. At the beginning and end of the experiment, spontaneous or brush ticklingevoked leg or abdomen movement was checked to ensure that the fly was still alive.

GCaMP6f fluorescence was imaged with a Leica SP5 II laser scanning confocal microscope equipped with a tandem scanner and HyD detector. The relevant area of the FB was visualized using the $25 \times$ water objective. Images were acquired at a speed of 8,000 lines per second with a line average of 1 , resulting in a collection time of $0.051 \mathrm{~ms}$ per frame at a resolution of $256 \mathrm{x}$ 126 pixels for a total of 7 minutes. The pinhole was opened to $200 \mu \mathrm{m}$.

Image analysis was performed following a previously described protocol (Musso et al., 2015; Plaçais and Preat, 2013; Plaçais et al., 2012). It was performed offline with a custom-written Matlab program. Light intensity was averaged over a region of interest delimited by hand and surrounding the projections of AB-FBI8 neurons on the FB layers 8 and 9. Three areas of interest $(\mathrm{ROI})$ were analyzed: the tips and the central part. From a given region of interest, the resulting time trace was normalized to a percent change of fluorescence $\left(100\left(F-F_{0}\right) / F_{0}\right)$, using a baseline value of the fluorescence $F_{0}$ that was estimated as the mean fluorescence over the whole acquisition. To remove long-term drift, a baseline resulting from the moving average over a 100-s time window was then subtracted from the signal. Thus, in subsequent frequency analyses, all frequency axes are presented starting at $0.01 \mathrm{~Hz}$. Given that signals are noisy, their amplitudes were estimated as the difference between the means of the $30 \%$ upper and lower quantiles of data points. For each signal, the power spectrum was computed and smoothed over a frequency window of $0.02 \mathrm{~Hz}$. Rhythmic spontaneous activity in the time domain resulted in a peak in the power spectrum that had a finite width, as oscillations are intrinsically noisy. A fit of a Lorentzian curve to the power spectrum was performed to yield an estimate of the central frequency of the peak, $f_{0}$, and the width of the peak at half its maximal value, $\Delta f$. $f_{0}$ defined the characteristic frequency of the oscillation and frequency fluctuations around $f_{0}$, and hence the regularity of the oscillation, could be quantified by the quality factor $Q$ $=f_{0} / \Delta f$ (Plaçais et al., 2009). A quality factor greater than 0.5 indicates that the zero frequency is excluded from the peak: this value was thus taken as a threshold to define a signal as rhythmically oscillating. When the fitting procedure converged to a value below 0.5 , it was thus irrelevant to define oscillating parameters, and $f_{0}$ and $Q$ were both assigned zero values. 
To plot average amplitude histograms, we calculated a mean amplitude value for the different ROI selected, and then averaged the mean values across all flies from the same condition.

Average power spectra across all animals from the same condition were obtained and were additionally smoothed over a $0.03-\mathrm{Hz}$ frequency window. Peaked average spectra (Figure 1D, Figure S1A-B, Figure S2A-C, Figure 4G, Figure S4A-B, Figure 5D, Figure S6G-H) were characterized by their mean frequency $f_{0}$ and a quality factor $Q$ calculated from $f_{0}$ and the width at half-height.

\section{Immunohistochemistry}

For GFP, Brain immunofluorescence was carried out as described previously (Chu et al., 2014). Primary antibodies used were Rabbit anti-GFP (1:1000, Invitrogen) and mouse anti-nc82 (1:50, DSHB). Secondary antibodies used were goat anti-Rabbit Alexa 488 (1:200, Invitrogen) and goat anti-mouse Alexa 568 (1:200, Invitrogen). For DenMark,Syt immunofluorescence, primary antibodies used were chicken anti-GFP (1:1000, Abcam), and rabbit anti-RFP (1:200, Rockland). Secondary antibodies used were goat anti-chicken Alexa 488 (1:200, Abcam) and goat anti-rabbit Alexa 647 (1:200, Thermo Fisher Scientific, Waltham, MA, \#A21245). For GRASP immunofluorescence, primary antibodies used were Mouse anti-GFP (1:100, Sigma, catalog \#G6539) and rabbit anti-DsRed (1:2,000, Clontech, \#632496). Secondary antibodies used were goat anti-Mouse Alexa 488 (1:200, Invitrogen) and goat anti-Rat Alexa 568 (1:200, Invitrogen). For Trans-Tango immunofluorescence, primary antobodies were Rabbit anti-GFP (1:1000, Invitrogen), mouse anti-nc82 (1:50, DSHB), and rat anti-HA (1:100, Roche). Secondary antibody used were goat anti-Rabbit Alexa 488 (1:200, Invitrogen), goat anti-mouse Alexa 568 (1:200, Invitrogen), and goat anti-rat Alexa 647 (1:200, Invitrogen). All images were acquired using a Leica SP5 II Confocal microscope with a 25x water immersion objective. All images were taken sequentially with a z-stack step size at $1 \mu \mathrm{m}$, a line average of 2 , line-scanning speed of $200 \mathrm{~Hz}$, and a resolution of $1024 \times 1024$ pixels. Images were processed in ImageJ (Schneider et al 2012).

\section{QUANTIFICATION AND STATISTICAL ANALYSIS}

Statistical tests were performed using GraphPad Prism six software. Descriptions and results of each test are provided in the figure legends. Sample sizes are indicated in the figure legends. Sample sizes were determined prior to experimentation based on the variance and effect sizes seen in prior experiments of similar types. Whenever possible, all experimental conditions were run in parallel and therefore have the same or similar sample sizes.

All replicates were biological replicates using different flies. Data for all quantitative experiments were collected on at least three different days, and behavioral experiments were performed with flies from at least two independent crosses. Specific definitions of replicates are as follows. For calcium imaging, each data point represents the activity of a single fly to the indicated condition. For binary choice behavioral tests, each data point represents the calculated preference for a group of 10 flies. For PER, each replicate is composed of 10 independent flies tested in parallel. For flyPAD and STROBE experiments, each data point is the calculated preference of an individual fly over the course of the experiment.

There were two conditions where data were excluded that were determined prior to experimentation and applied uniformly throughout. First, in calcium imaging experiments, all the data from a fly were removed if either: a) there was too much movement during the recording to reliably quantify the response; or b) flie were dead at the end of the recording. Second, for flyPAD and STROBE experiments, the data from individual flies were removed if the fly did not pass a set minimum threshold of sips (10), or the data showed hallmarks of a technical malfunction (rare). 
bioRxiv preprint doi: https://doi.org/10.1101/2021.04.08.439043; this version posted April 9, 2021. The copyright holder for this preprint (which was not certified by peer review) is the author/funder, who has granted bioRxiv a license to display the preprint in perpetuity. It is made available under aCC-BY-NC 4.0 International license.

All the quantitative data used for statistical tests can be found as supplements for each figure. 


\section{FIGURES}

A

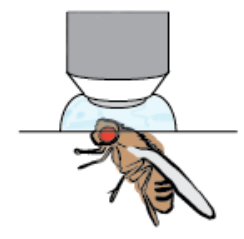

B
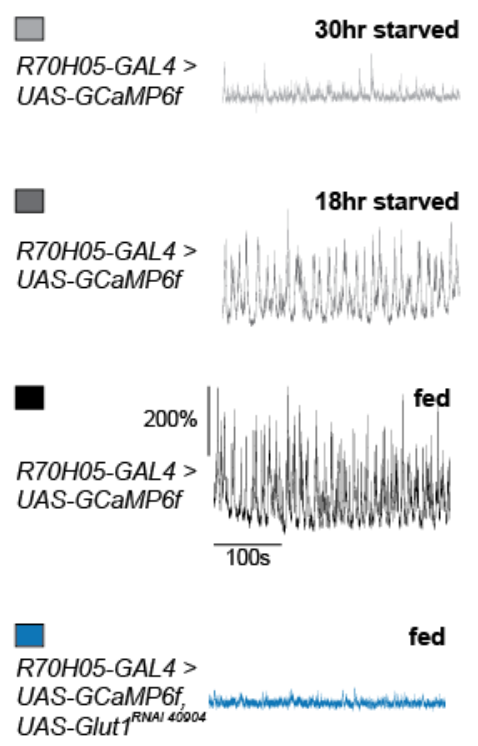

UAS-Glut1 $1^{\text {RNA/ } 40004}$

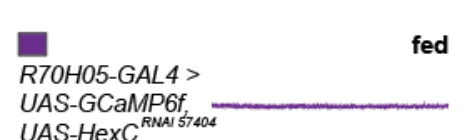

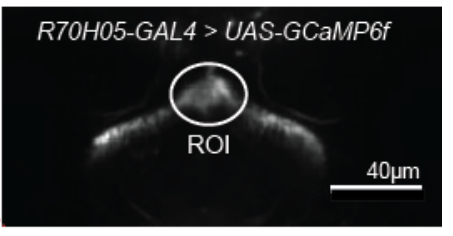

C
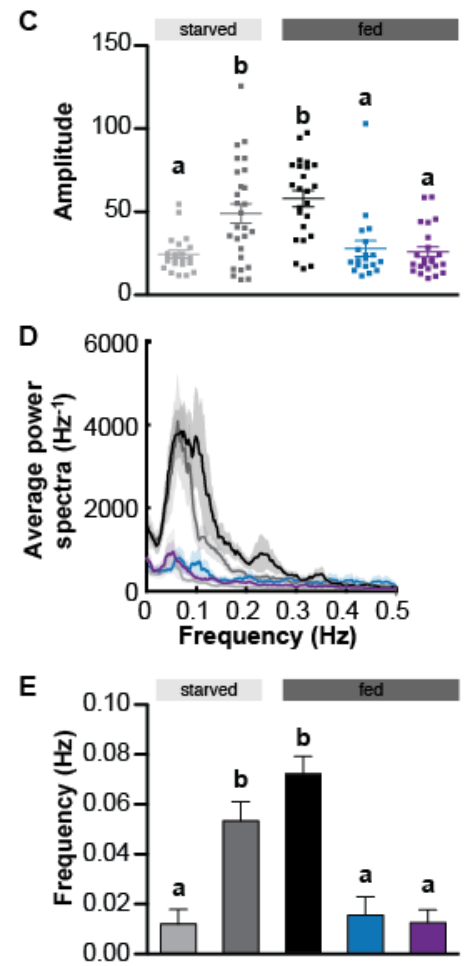

$\mathbf{F}$

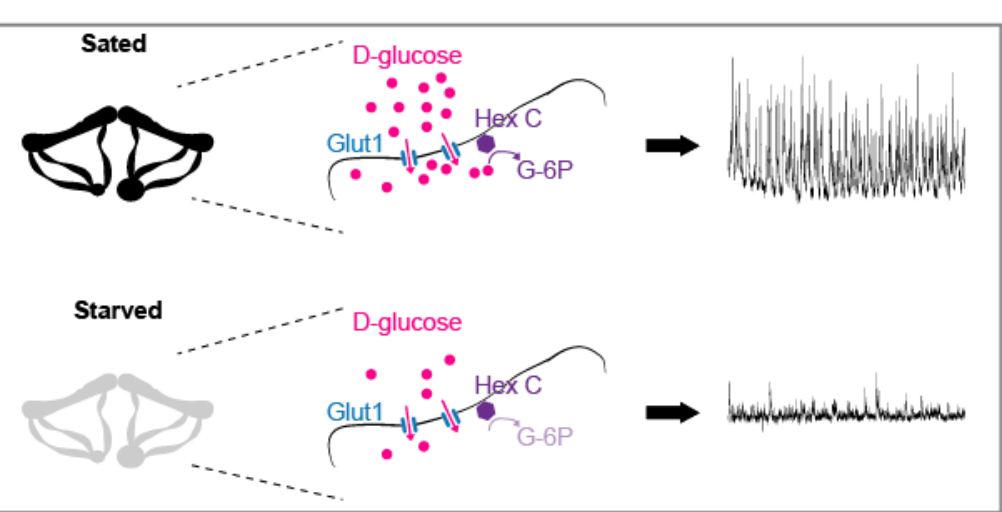

Figure 1. Starvation regulates Fan-Shaped Body oscillations

(A) Schematic of imaging preparation to monitor calcium oscillations (left) with GCaMP6f signal from R7OH05-GAL4 expression in the dFB (right). (B) Calcium traces from R70H05-GAL4 > UAS-GCamP6f flies after different periods of starvation or expressing RNAi against Glut1 and HexC. (C) Amplitudes of dFB neurons oscillations. (D) Power spectra of dFB neurons oscillations. (E) Frequencies of dFB neurons oscillations. (F) Model: in sated flies, D-glucose enter the dFB neurons through Glut1 and trigger oscillations through the activity of HexC; in starved flies, the low availability of D-glucose prevents oscillations. Values represent mean \pm SEM. $n=19-27$. Statistical tests: one-way ANOVA and Tukey posthoc; different letters represent significant differences $p<0.05$. See also Figure $\mathrm{S} 1$. 


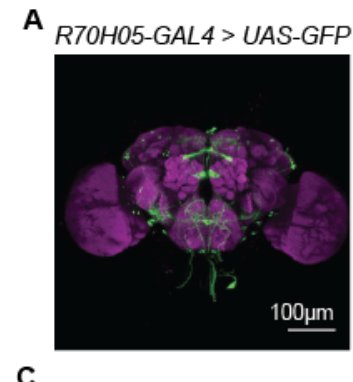

B

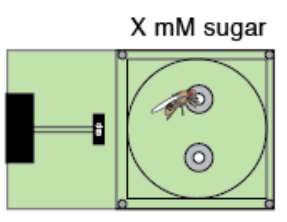

$1 \%$ agar

$\mathbf{F}$
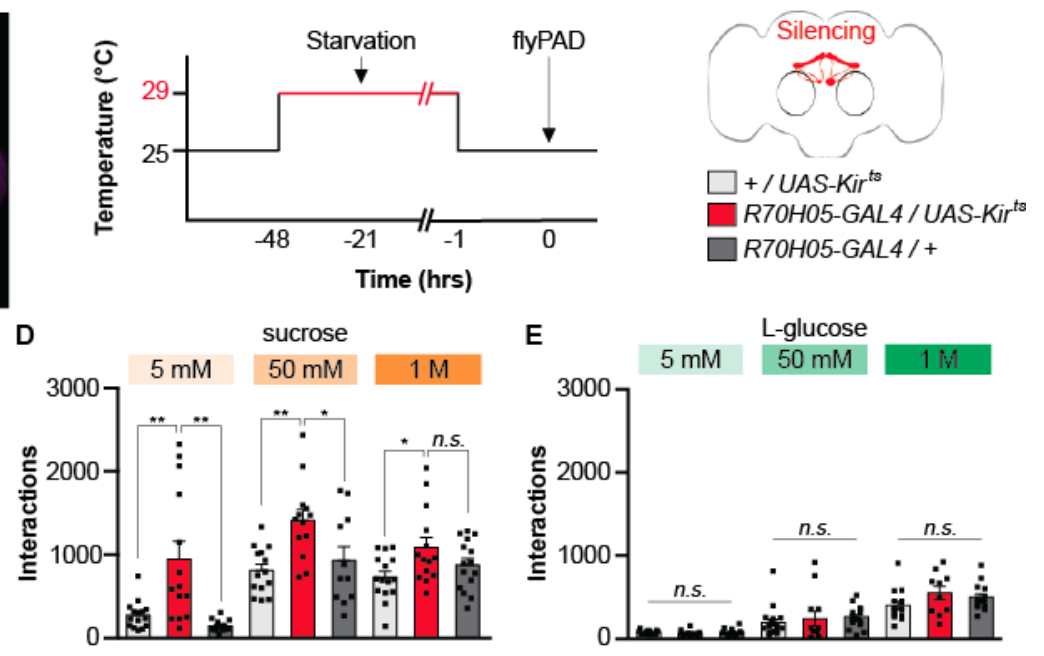

G

L-glucose

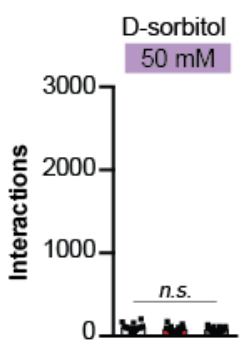

$50 \mathrm{mM}$
D-sorbitol
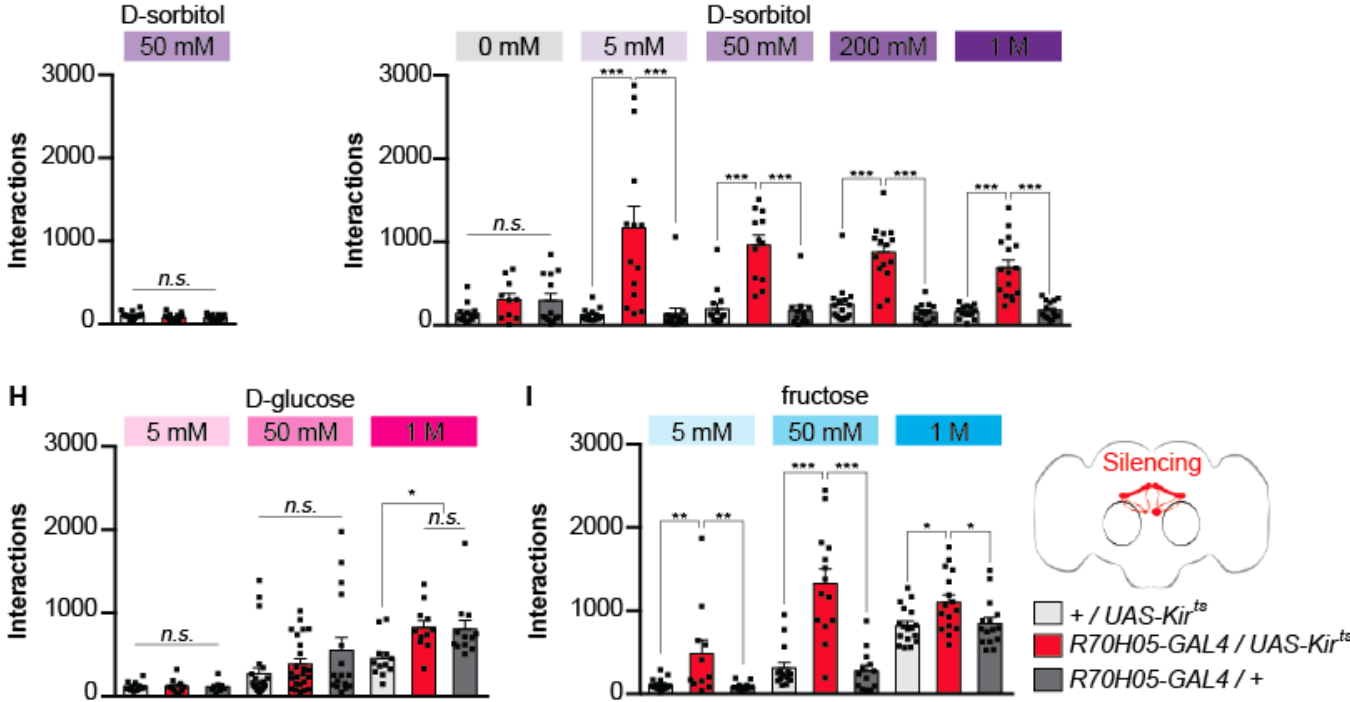

Figure 2. Silencing AB-FBI8 neurons increases fructose feeding

(A) Immunofluorescent detection of UAS-GFP driven by R7OH05-GAL4. (B) Experimental timeline: flies are placed at 29 degrees for $47 \mathrm{hrs}$ and starved for $18 \mathrm{hrs}$, and experiments are performed at 25 degrees. (C) Experimental setup: one channel is filled with sugar and the other one is filled with $1 \%$ agar. (D) Effect of silencing AB-FBI8 neurons on flies' interactions with various concentrations of sucrose $(5,50$ and 1000 $\mathrm{mM} ; n=16-21$ ). (E) Effect of silencing AB-FBI8 neurons on flies' interactions with various concentrations of L-glucose (5, 50 and $1000 \mathrm{mM} ; n=10-19)$. (F) Effect of silencing AB-FBI8 neurons on flies' interactions with $50 \mathrm{mM}$ of D-sorbitol $(n=15)$. (G) Effect of silencing AB-FBI8 neurons on flies' interactions with 50 $\mathrm{mM}$ of L-glucose mixed with various concentrations of D-sorbitol $(0,5,50,200$ and $1000 \mathrm{mM} ; n=10-16)$. (H) Effect of silencing AB-FBI8 neurons on flies' interactions with various concentrations of D-glucose (5, 50 and $1000 \mathrm{mM} ; n=8-26$ ). (I) Effect of silencing AB-FBI8 neurons on flies' interactions with various concentrations of fructose $(5,50$ and $1000 \mathrm{mM} ; n=11-17)$. Values represent mean \pm SEM. Statistical tests: one-way ANOVA and Tukey post-hoc; ns: $p>0.05,{ }^{*} p<0.05,{ }^{* *} p<0.01,{ }^{* * *} p<0.001$. 
bioRxiv preprint doi: https://doi.org/10.1101/2021.04.08.439043; this version posted April 9, 2021. The copyright holder for this preprint (which was not certified by peer review) is the author/funder, who has granted bioRxiv a license to display the preprint in perpetuity. It is made available under aCC-BY-NC 4.0 International license.

A

C

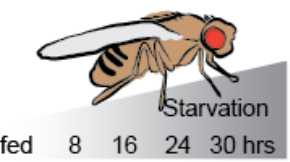

E

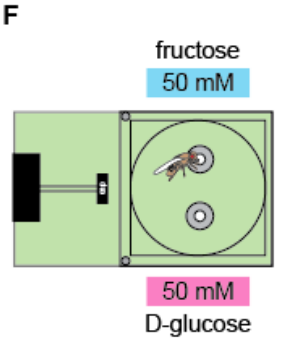

B
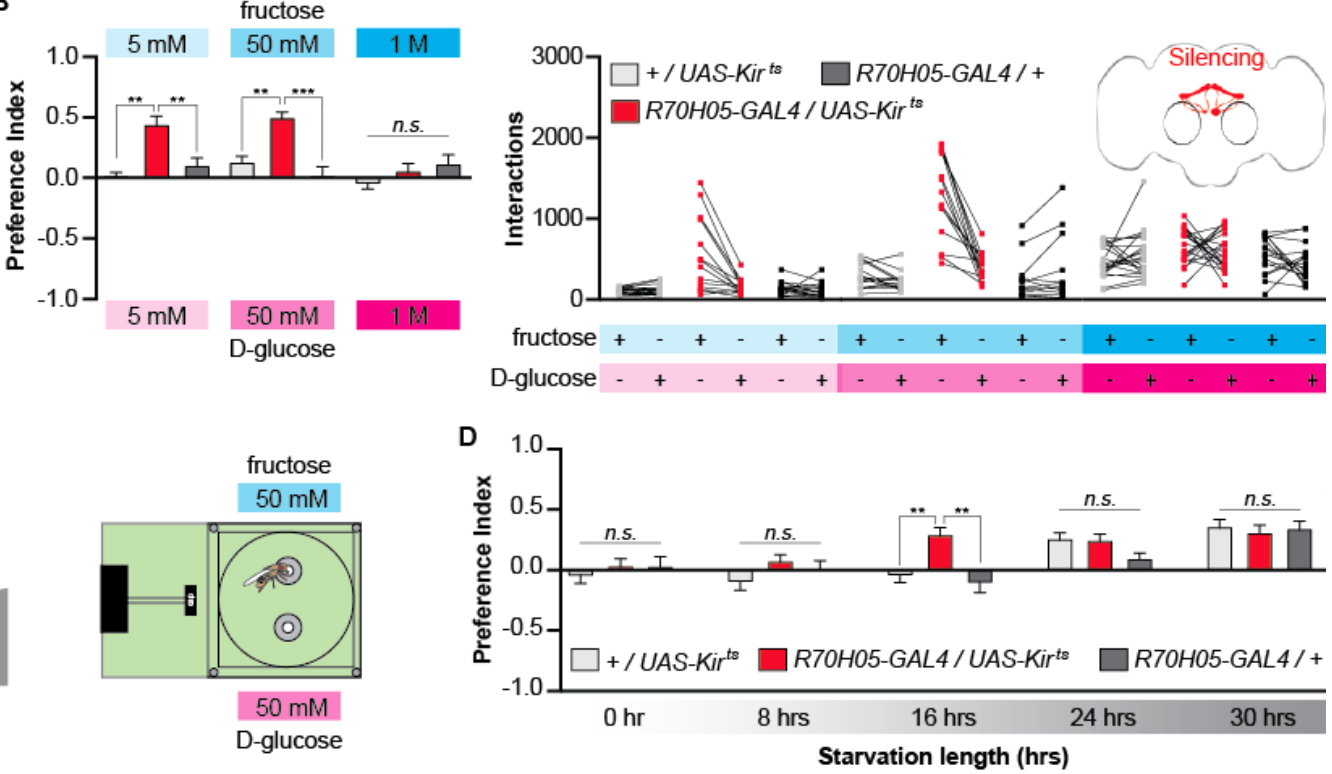

$50 \mathrm{mM}$

D-glucose

$50 \mathrm{mM}$
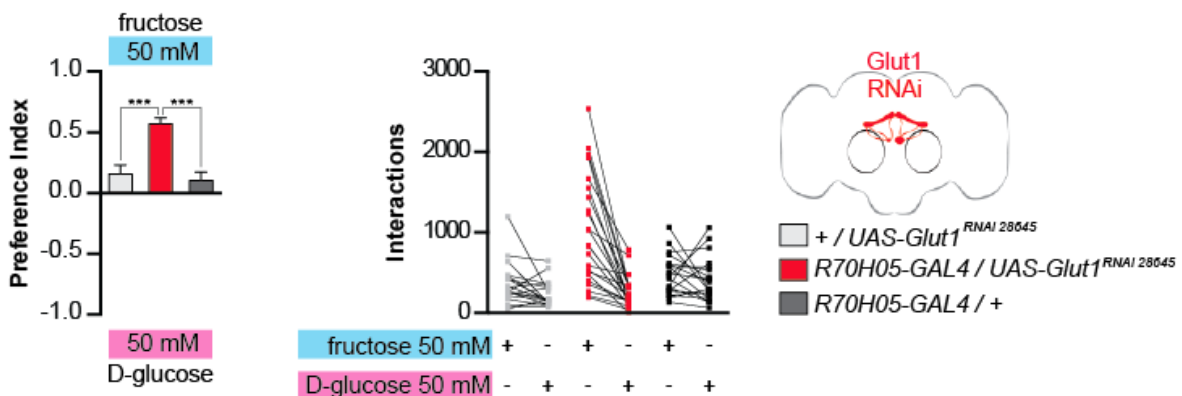

fructose $50 \mathrm{mM}+-++$

D-glucose $50 \mathrm{mM}-+++$

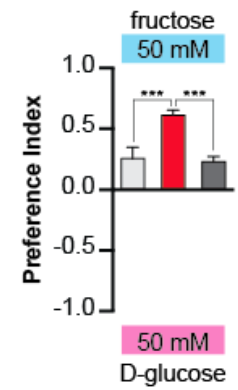

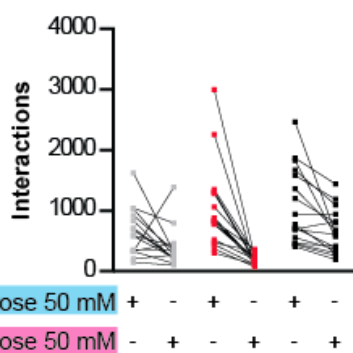

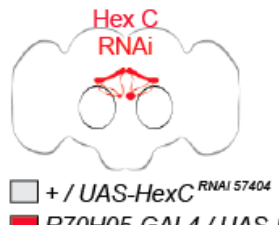

$\square$ R7OH05-GAL4 / UAS-HexC RNAI 57004

$\square R 70 H 05-G A L 4 /+$

G

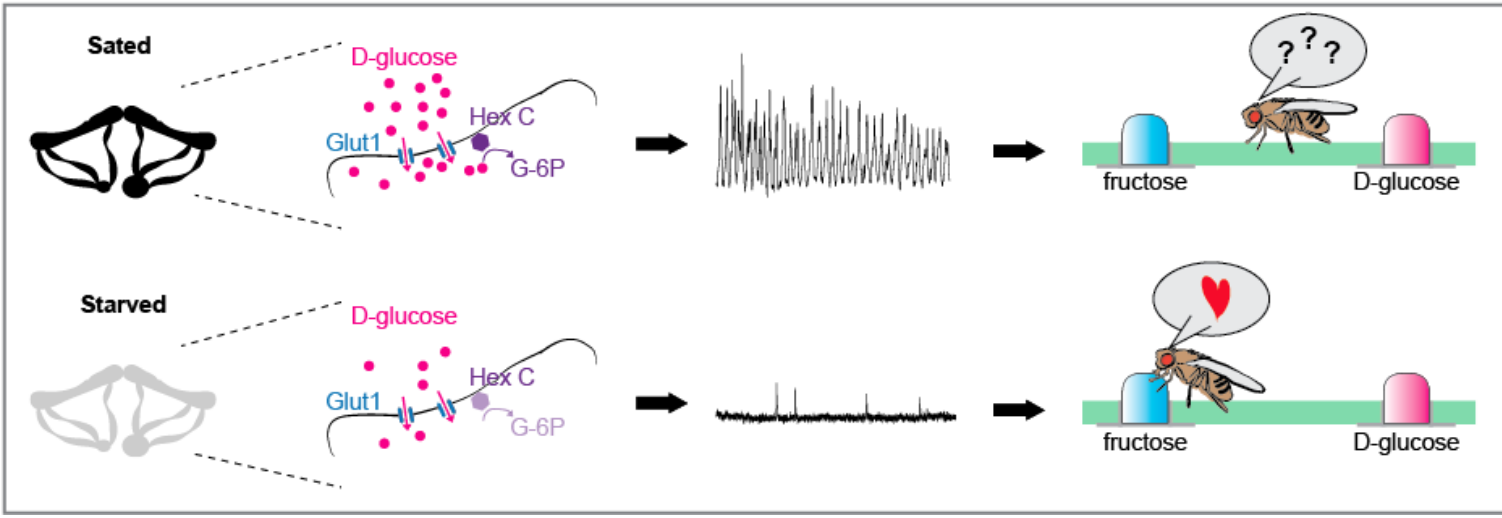


bioRxiv preprint doi: https://doi.org/10.1101/2021.04.08.439043; this version posted April 9, 2021. The copyright holder for this preprint (which was not certified by peer review) is the author/funder, who has granted bioRxiv a license to display the preprint in perpetuity. It is made available under aCC-BY-NC 4.0 International license.

Figure 3: Fructose feeding preference relies on starvation

(A) Experimental setup: left channel is filled with fructose and the right channel is filled with the same concentration of D-glucose. (B) Effect of silencing AB-FBI8 neurons on flies' preference between fructose and D-glucose at $5 \mathrm{mM}, 50 \mathrm{mM}$, and $1 \mathrm{M}$ (left); and their corresponding interactions (right; $n=13-21$ ). (C) Experimental setup: Flies are starved for different amounts of time and given the choice between $50 \mathrm{mM}$ fructose and $50 \mathrm{mM}$ D-glucose. (D) Effect of starvation length on preference between $50 \mathrm{mM}$ fructose and $50 \mathrm{mM}$ D-glucose in controls and flies with silenced AB-FBI8 neurons $(n=21-36)$. (E) Effect of knocking down Glut1 in AB-FBI8 neurons on the preference between $50 \mathrm{mM}$ fructose and D-glucose $(n=19-23)$. F) Effect of knocking down HexC in AB-FBI8 neurons on the preference between $50 \mathrm{mM}$ fructose and Dglucose $(n=15-18)$. (G) Model for regulation of fructose preference by AB-FBI8 activity. Values represent mean \pm SEM. Statistical tests: one-way ANOVA and Tukey post-hoc; ns: $p>0.05,{ }^{* \star} p<0.01$, ${ }^{* * *} p<0.001$. See also Figure S1, S2 and S3. 

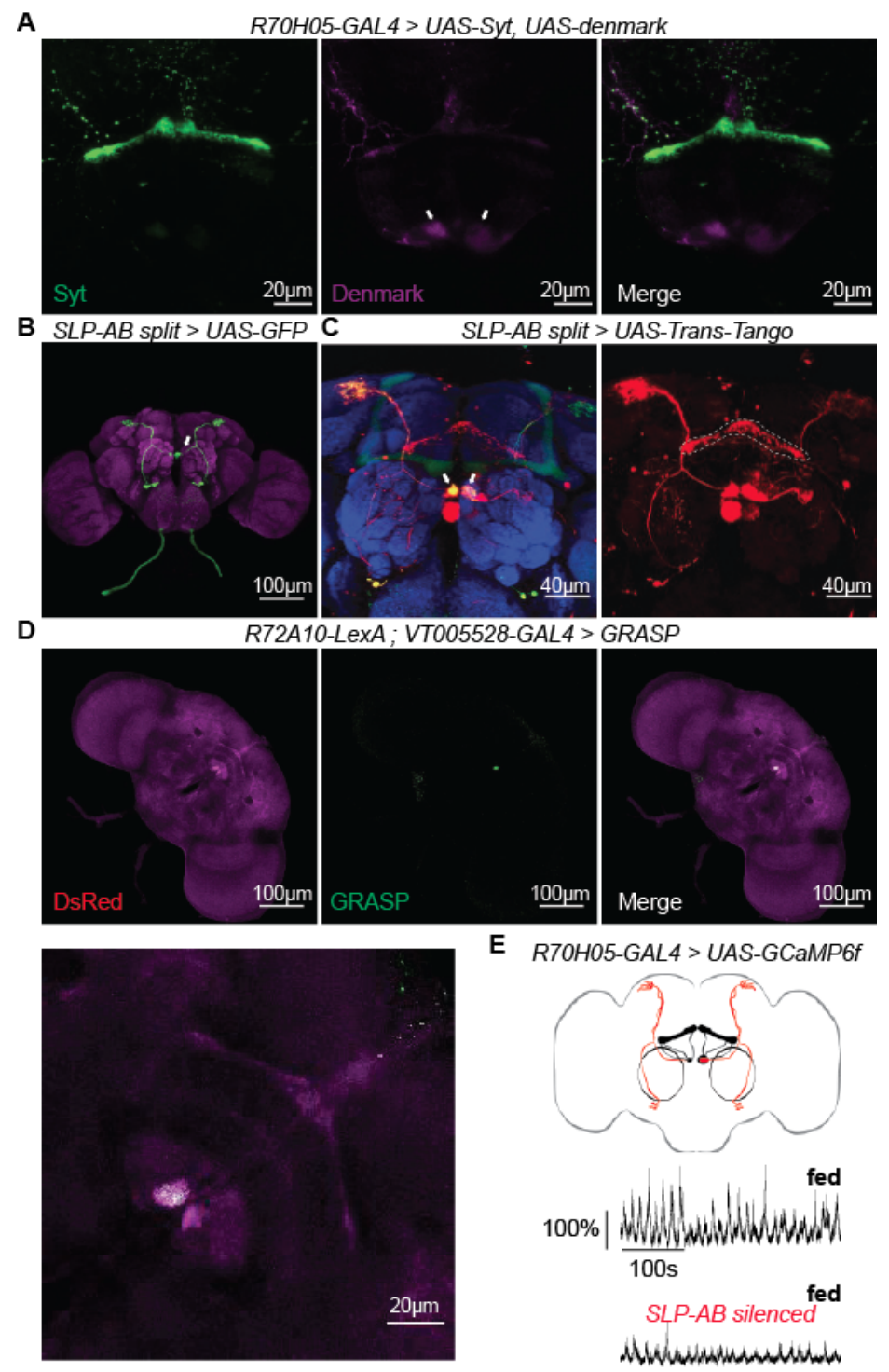

E R7OH05-GAL4 > UAS-GCaMP6f
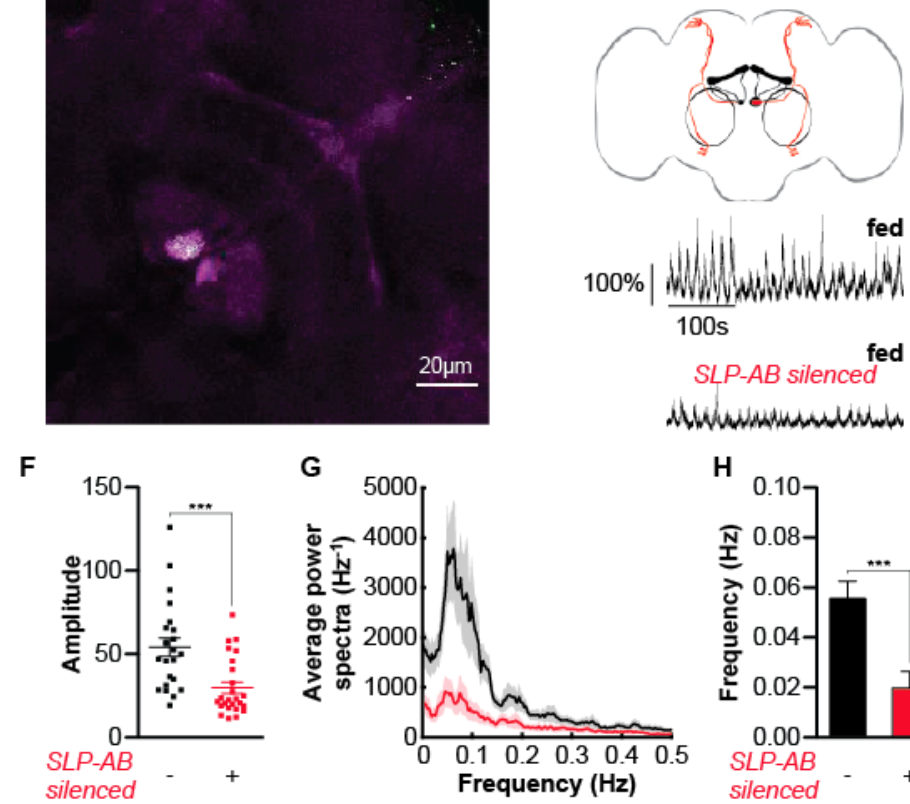

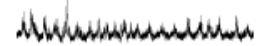

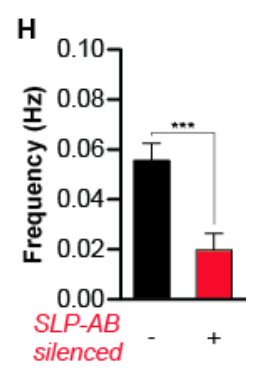

Figure 4. SLP-AB neurons contact AB-FBI8 neurons on the asymmetric body and modulate oscillations

(A) Immunofluorescent detection of UAS-Syt (green) and UAS-Denmark (magenta) driven by R7OHO5GAL4. Arrows show dendritic compartment localized on the asymmetric body. (B) Immunofluorescent detection of UAS-GFP driven by SLP-AB split-GAL4. Arrows show projections to the asymmetric body. (C) Trans-Tango expression driven by SLP-AB split-Gal4. Arrows show the contact between SLP-AB neurons and post synaptic targets, and dotted line outlines trans-Tango expression in the Fan-shaped body layer 8. (D) GRASP between AB-FBI8 and SLP-AB neurons produces a signal at the asymmetric 
bioRxiv preprint doi: https://doi.org/10.1101/2021.04.08.439043; this version posted April 9, 2021. The copyright holder for this preprint (which was not certified by peer review) is the author/funder, who has granted bioRxiv a license to display the preprint in perpetuity. It is made available under aCC-BY-NC 4.0 International license.

body. (E) Calcium trace from R70H05-GAL4 > UAS-GCamP6f (top) and R70H05-GAL4; R72A10-LexA > UAS-GCamP6f; LexAop-tnt (bottom) fed flies. (F) Amplitudes of oscillations. (G) Power spectra of oscillations. $(H)$ Frequencies of oscillations. Imaging data are from $\mathrm{ROI}$ placed in the middle part of $A B-$ FBI8 neurons. Values represent mean \pm SEM. $n=23-25$. Statistical tests: $t$-test, ${ }^{* * *} p<0.001$. See also Figure S4. 
A

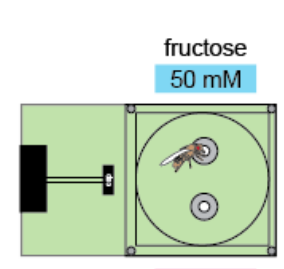

$50 \mathrm{mM}$

D-glucose

B

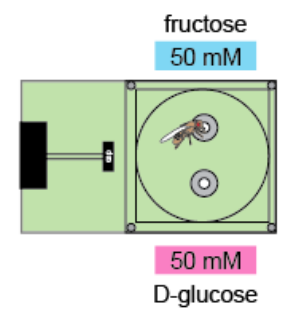

C

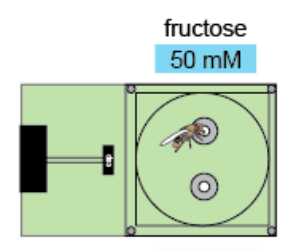

$50 \mathrm{mM}$

D-glucose
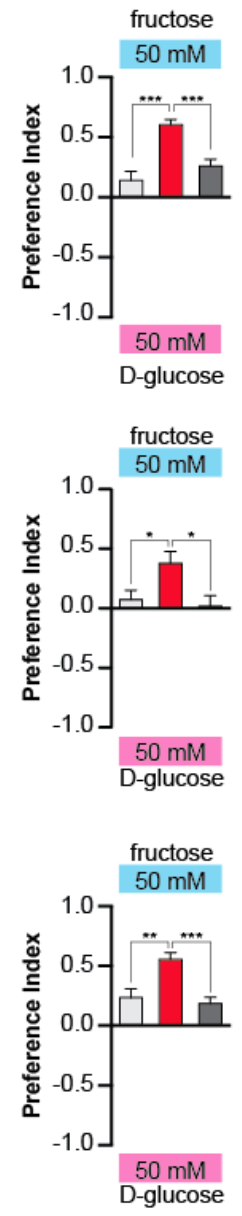

D

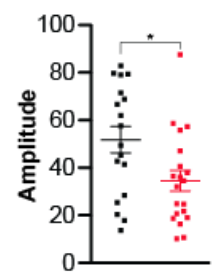

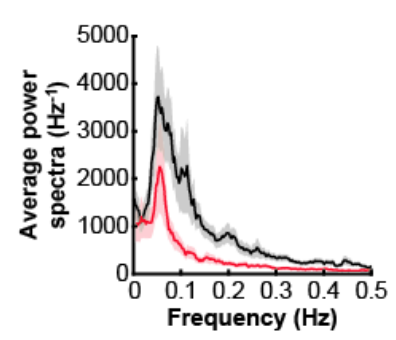
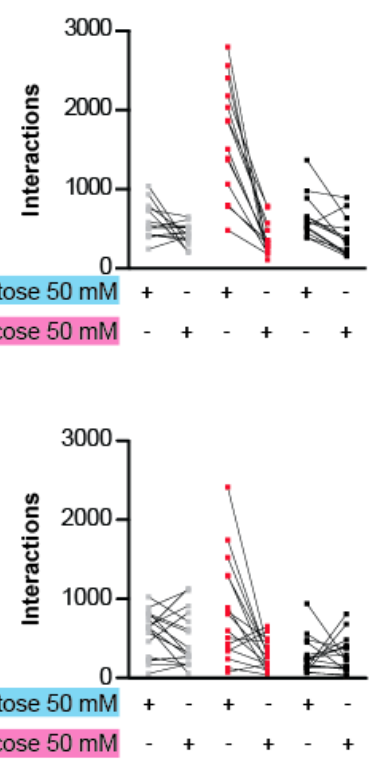

fructose $50 \mathrm{mM}$
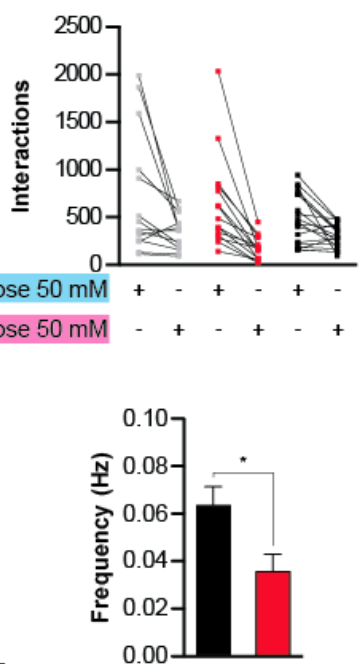

E

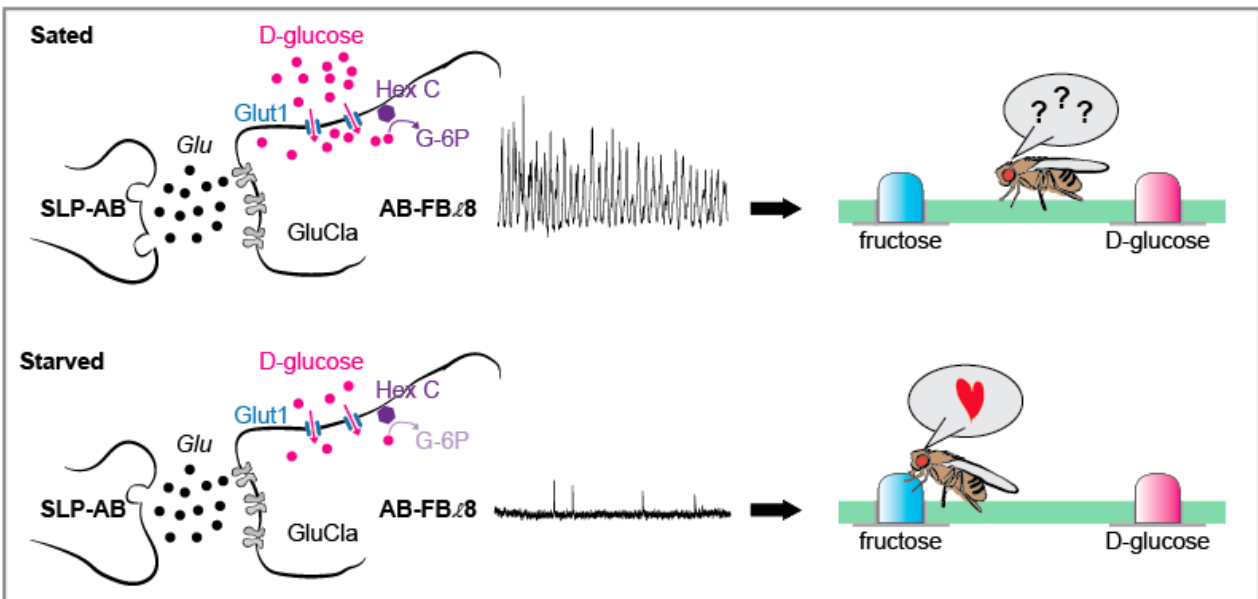


bioRxiv preprint doi: https://doi.org/10.1101/2021.04.08.439043; this version posted April 9, 2021. The copyright holder for this preprint (which was not certified by peer review) is the author/funder, who has granted bioRxiv a license to display the preprint in perpetuity. It is made available under aCC-BY-NC 4.0 International license.

Figure 5. Glutamatergic SLP-AB neurons are positively connected to AB-FBI8 neurons

(A) Effect of silencing SLP-AB neurons on flies' preference between fructose and D-glucose, and their corresponding interactions $(n=13-14)$. (B) Effect of knocking down Vglut in SLP-AB neurons on flies' preference between fructose and D-glucose, and their corresponding interactions $(n=16-19)$. (C) Effect of knocking down GluCl $\alpha$ in AB-FBI8 neurons on flies' preference between fructose and D-glucose, and their corresponding interactions $(n=14-19)$.(D) Knocking down GluCl $\alpha$ in AB-FBI8 neurons moderately inhibits oscillations $(n=18-20)$.(E) Glutamatergic input from SLP-AB is permissive for AB-FBI8 oscillations). Values represent mean \pm SEM. Statistical tests: one-way ANOVA and Tukey post-hoc for behavior and $t$-test for imaging; ns: $p>0.05,{ }^{* *} p<0.01,{ }^{* * *} p<0.001$. See also Figure S5 and S6. 
A

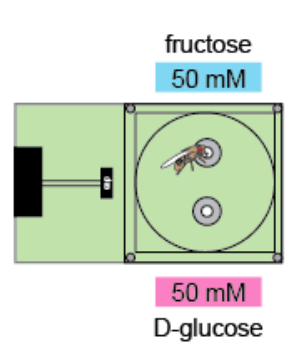

B

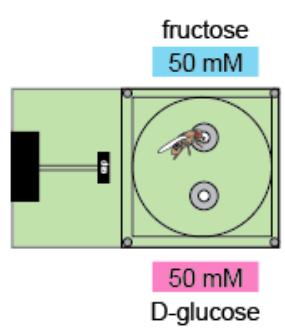

C
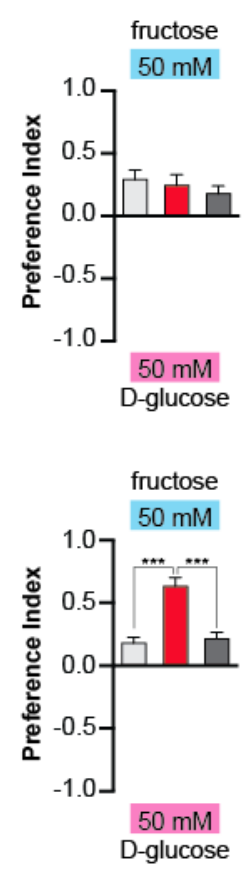

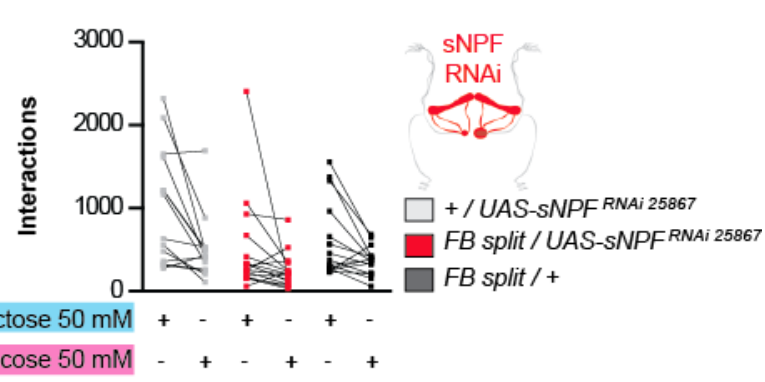

D-glucose $50 \mathrm{mM}-+++$

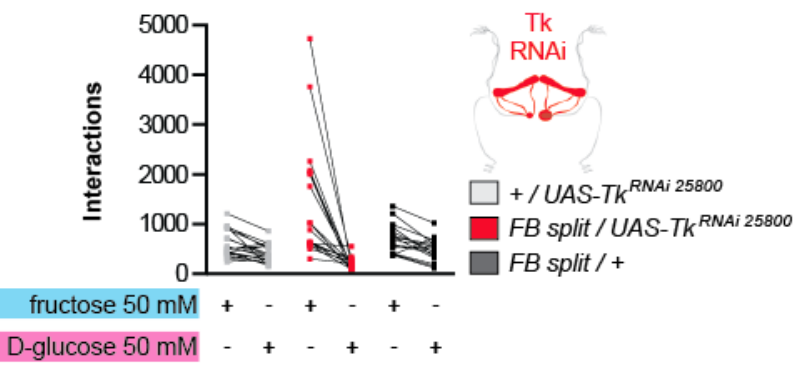

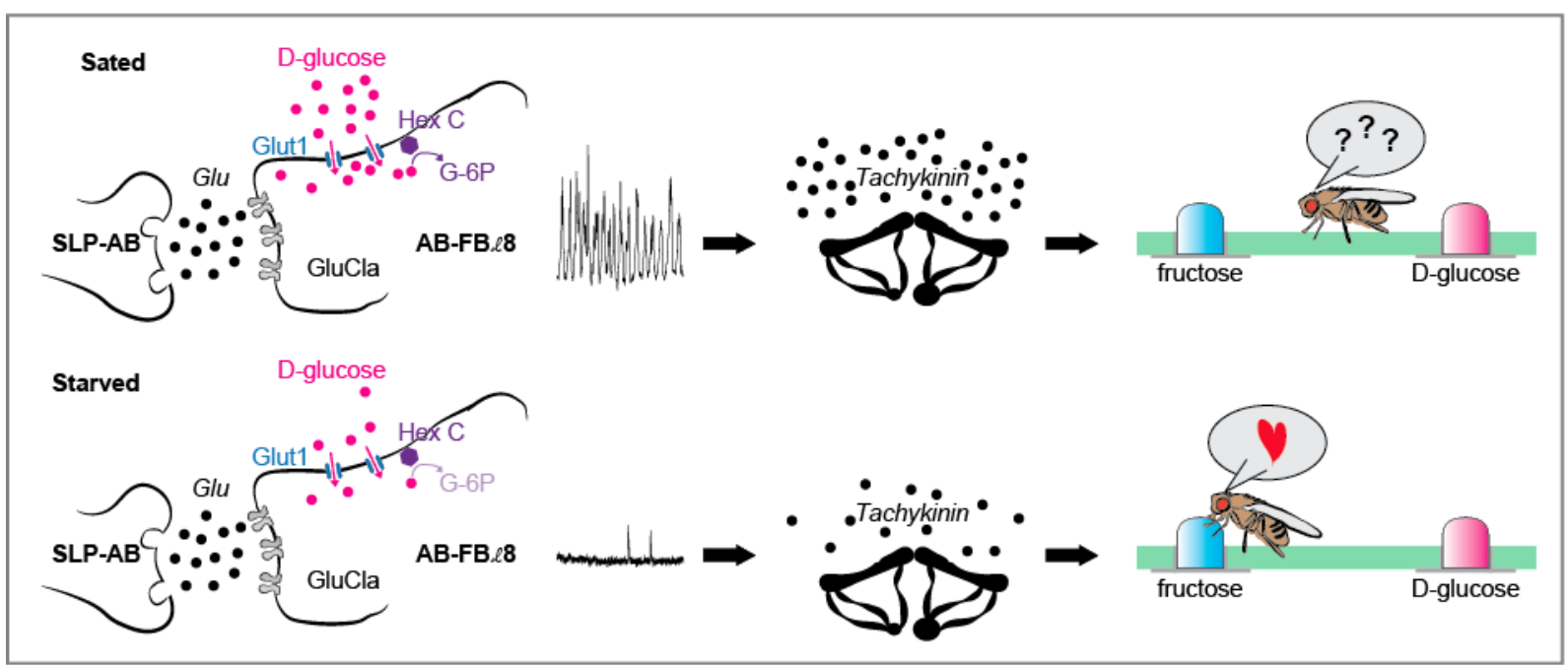

Figure 6. AB-FBI8 neurons regulate fructose-feeding preference through tachykinin secretion

(A) Effect of knocking down sNPF in AB-FBI8 neurons on flies' preference between fructose and Dglucose, and their corresponding interactions $(n=14-18)$. (B) Effect of knocking down tachykinin in ABFBI8 neurons on flies' preference between fructose and D-glucose, and their corresponding interactions $(n=16-20)$. (C) Tachykinin secretion in sated flies inhibit fructose feeding preference. Values represent mean \pm SEM. Statistical tests: one-way ANOVA and Tukey post-hoc; ns: $p>0.05,{ }^{* \star *} p<0.001$. See also Figure S7. 
A

B
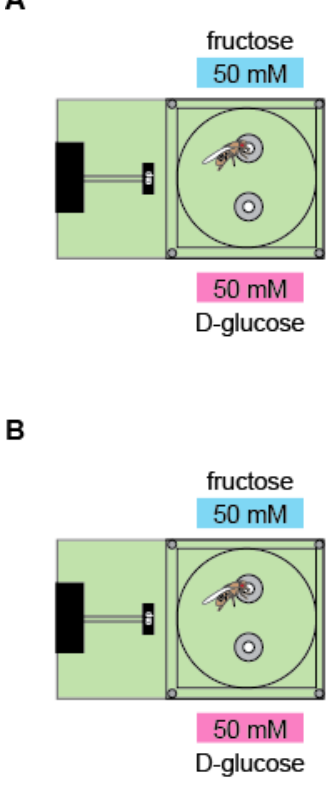

C

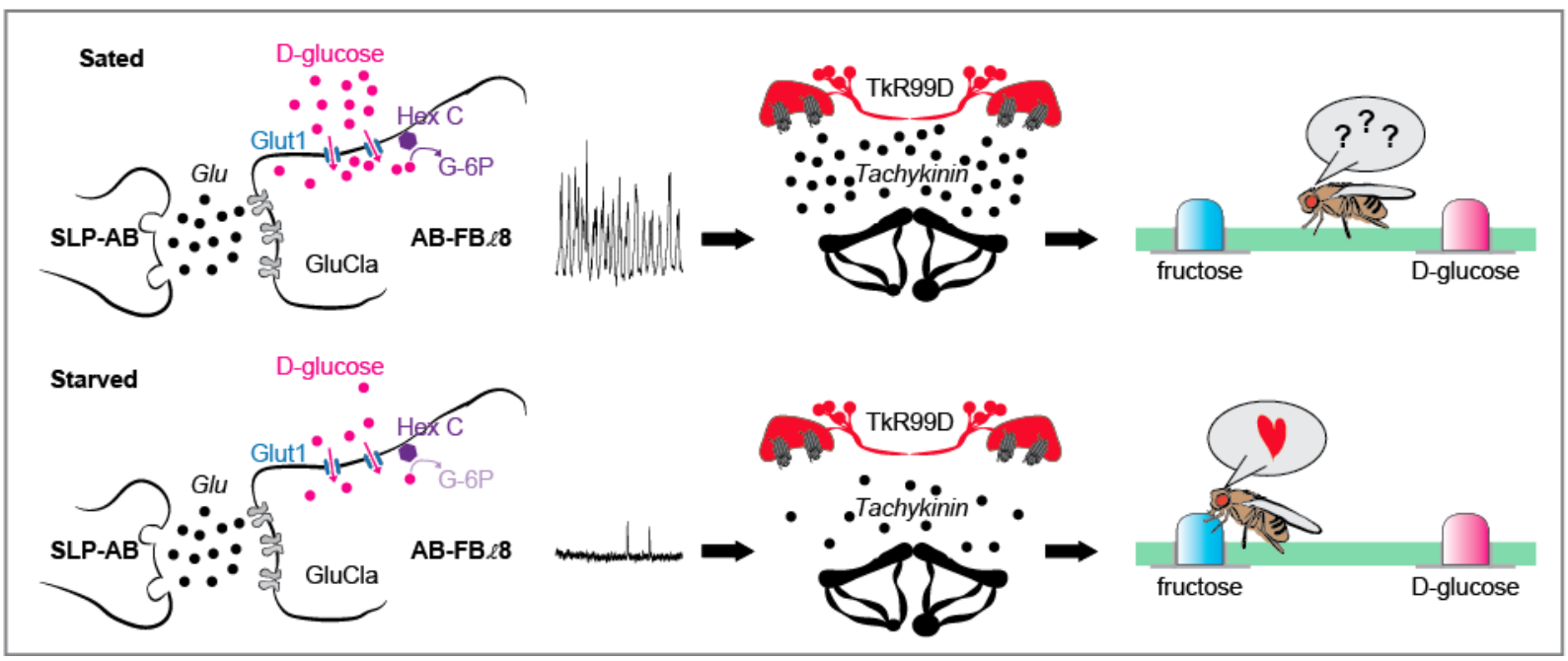

Figure 7. AB-FBI8 neurons' tachykinin secretion regulates fructose feeding preference through activation of the brain fructose sensor Gr43a

(A) Effect of knocking down TkR99D in brain Gr43a neurons on flies' preference between fructose and Dglucose, and their corresponding interactions $(n=18-26)$. (B) Effect of knocking down TkR86C in brain Gr43a neurons on flies' preference between fructose and D-glucose, and their corresponding interactions $(n=14-19)$. (C) Model: tachykinin secretion in sated flies inhibits fructose feeding preference by acting on TkR99D expressed in Gr43a neurons. Values represent mean \pm SEM. Statistical tests: one-way ANOVA and Tukey post-hoc; ns: $p>0.05,{ }^{*} p<0.05,{ }^{* * *} p<0.001$. See also Figure S8. 
A

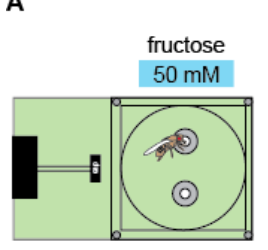

$50 \mathrm{mM}$

D-glucose

B

(light) $1 \%$ agar

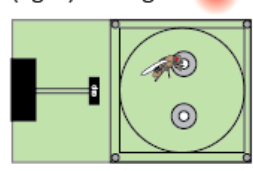

(no light) 1\% agar

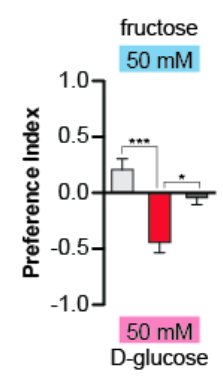

Gr43aCha7.4kb-Gal80 > UAS-CsChrimson $\square$ No retinal

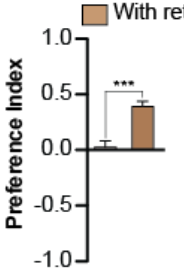

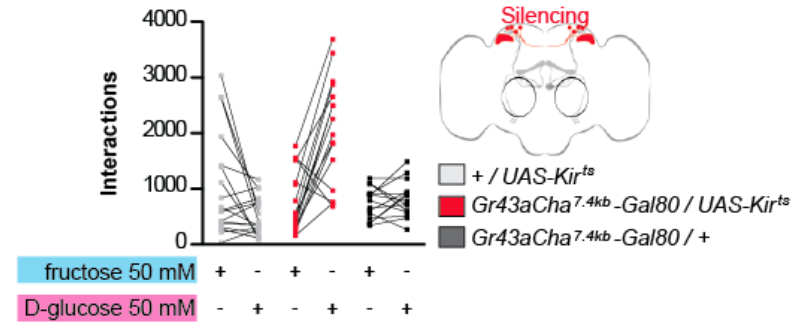

Gr43aCha7.4kb-Gal80 > UAS-CsChrimson No ret Ret

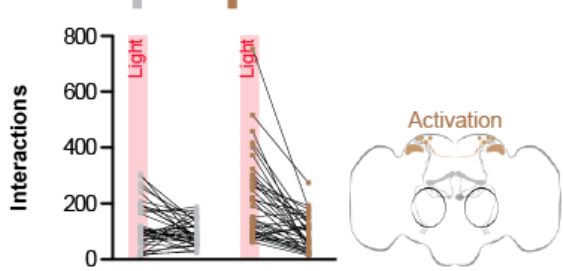

C

(1) Starvation promotes foraging behavior

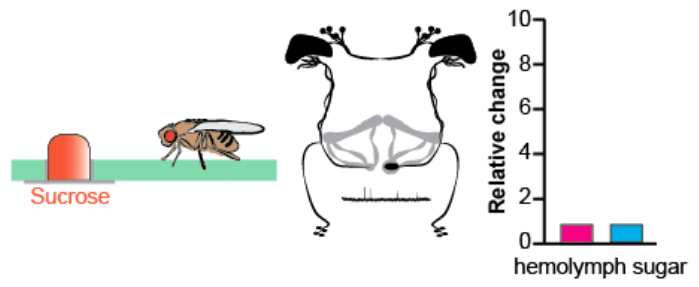

(3) Hemolymph glucose rise to a AB-FB $\& 8$ activating threshold
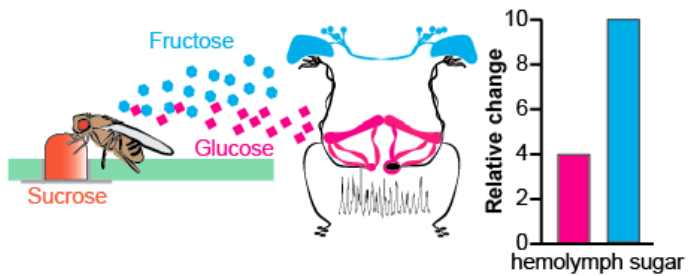

(2) Sugar ingestion promotes fast hemolymph fructose elevation tiggering
prolonged ingestion through brain Gr43a neurons activation
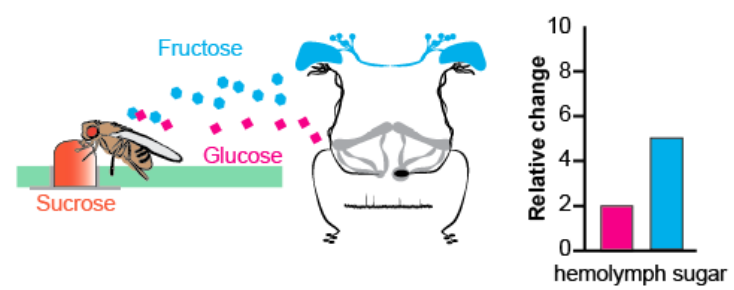

(4) Tachykinin inhibits brain Gr43 neurons inducing feeding termination
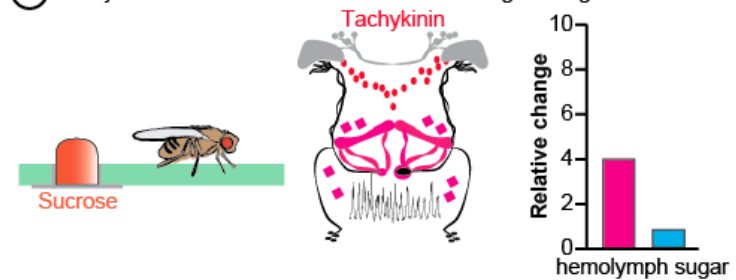

Figure 8. Brain Gr43a neurons acutely regulate fructose feeding

(A) Effect of silencing brain Gr43a neurons on flies' preference between fructose and D-glucose, and their corresponding interactions $(n=15-19)$. (B) Preference in the STROBE for agar paired with light activation of Gr43a neurons expressing CsChrimson, and their corresponding interactions $(n=40-41)$. (C) Model for how fructose serves as a cue for promoting sugar ingestion, and how rising glucose levels signal satiety through $A B-F B \mid 8$, which then inhibits sensitivity to fructose and terminates feeding. Values represent mean \pm SEM. Statistical tests: one-way ANOVA and Tukey post-hoc; ns: $p>0.05,{ }^{*} p<0.05,{ }^{* \star *} p<0.001$. 